Portland State University

PDXScholar

1985

\title{
The significance of hypovolemia in dehydrational death in anurans
}

Peter Blair Kimmel

Portland State University

Follow this and additional works at: https://pdxscholar.library.pdx.edu/open_access_etds

Part of the Biology Commons, and the Physiology Commons Let us know how access to this document benefits you.

Recommended Citation

Kimmel, Peter Blair, "The significance of hypovolemia in dehydrational death in anurans" (1985). Dissertations and Theses. Paper 3432.

https://doi.org/10.15760/etd.5315

This Thesis is brought to you for free and open access. It has been accepted for inclusion in Dissertations and Theses by an authorized administrator of PDXScholar. Please contact us if we can make this document more accessible: pdxscholar@pdx.edu. 
AN ABSTRACT OF THE THESIS OF Peter Blair Kimmel for the Master of Science in Biology presented August 22, 1985. Title: The Significance of Hypovolemia in Dehydrational Death in Anurans.

APPROVED BY MEMBERS OF THE THESIS COMMITTEE:

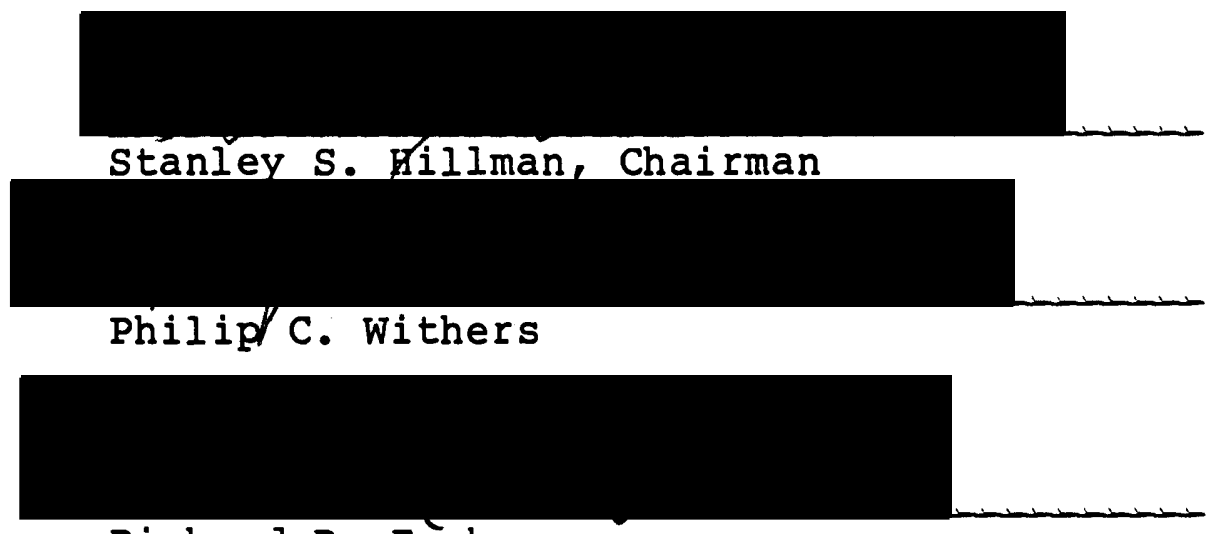

Richard B. Forbes

The importance of hypovolemia in dehydrational death was assessed in two anuran species. Xenopus laevis, a species which experiences a significant reduction in circulating plasma volume with dehydration, was used to evaluate the role of sympathetic reflex compensation in hypovolemia. Adrenergic blockade with propranolol or phenoxybenzamine produced no significant reduction in dehydration tolerance in this species, although $\beta$-blockade with propranolol appeared to have a minor effect. The role of hypovolemic shock in the terminal circulatory collapse 
that precedes death in dehydrating anurans was investigated in the toad, Bufe marinus. The activity of lysosomal proteinases (cathepsins) was used as an indicator of the shock state. An assay was developed for the determination of cathepsin activity in toad plasma and was used to demonstrate the presence of proteinases similar in $\mathrm{pH}$ dependence to mammalian cathepsins $B I$ and D. Plasma cathepsin D-type activity increased with dehydration in toads but was not significantly different from the activity in controls or in toads subjected to splanchnic artery occlusion. Toads appear to maintain plasma volume to 208 water loss at the expense of other extracellular fluids. These results do not support the hypothesis that hypovolemia is a direct cause of dehydrational death in anurans. 
THE SIGNIFICANCE OF HYPOVOLEMIA IN

DEHYDRATIONAL DEATH IN ANURANS

by

PETER BLAIR KIMMEL

A thesis submitted in partial fulfillment of the requirements for the degree of

\author{
MASTER OF SCIENCE \\ in \\ BIOLOGY
}

Portland State University 
TO THE OFFICE OF GRADUATE STUDIES AND RESEARCH:

The members of the Committee approve the thesis of Peter Blair Kimmel presented August 22, 1985.

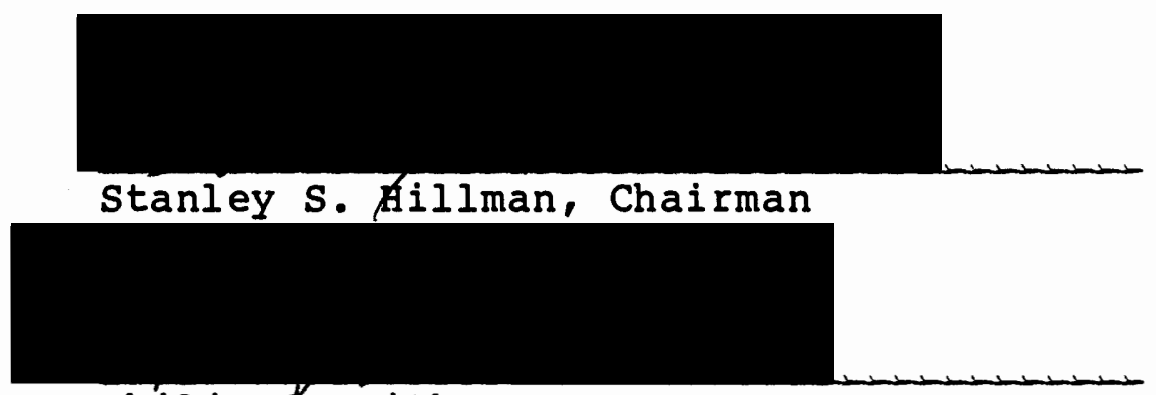

Philip . Withers

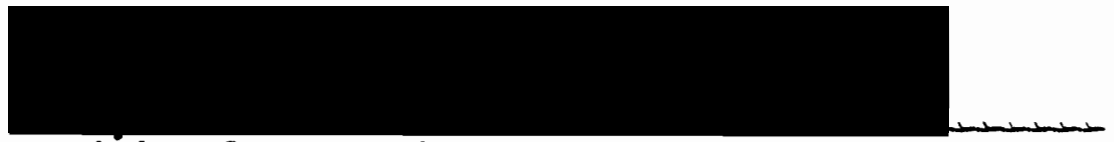

Richard B. Forbes

\section{APPROVED :}
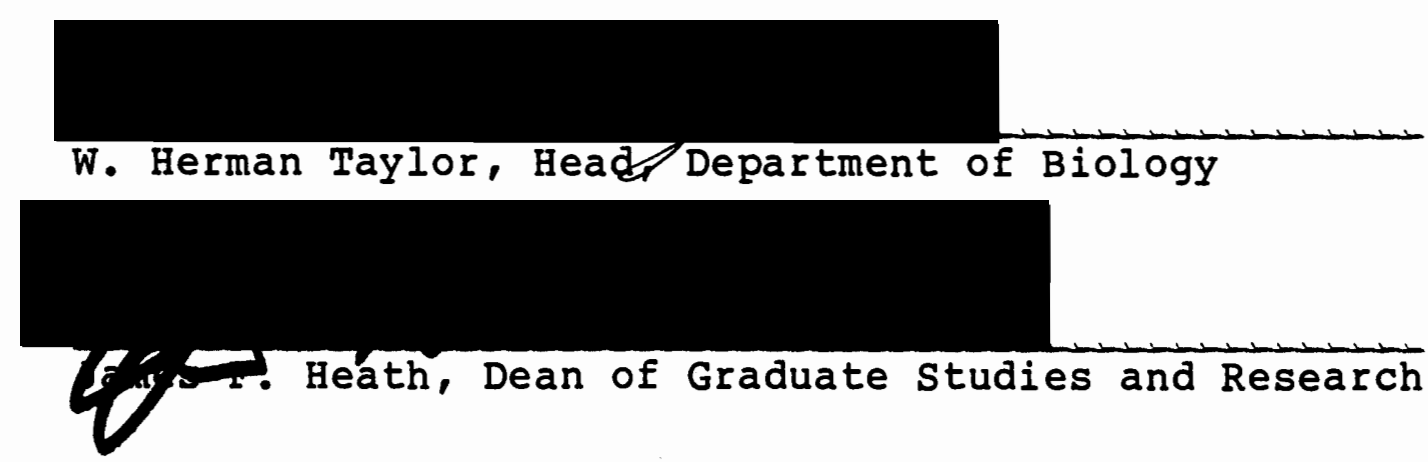


\section{ACKNOWLEDGEMENTS}

The L-cysteine hydrochloride used in this project was a generous gift from Sigma Chemical Co.

I would like to express my sincere thanks to a cast of characters almost too numerous to mention:

* To Stan Hillman, my advisor, who -- more often than not -- was the driving force in the equation. If not for his guidance and friendship I would never have made it this far.

* To Phil Withers and Richard Forbes for helpful comments and criticisms of this work and an invaluable education in the classroom and the laboratory.

* To those who were there in the beginning: Rick Moore, Tom Solberg, Scott Landrey, and especially Dale Robinson, co-inventor of the Megadart and the Woman Tamer. * To those who were there at the end: Andy zygmunt, Gary Haight, and Mike Hedrick -- whose help with the plasma sodiums insured a "good grouping."

* To my father, who had no idea what I was doing but supported me anyway.

* To the crew of the Foghorn for giving meaning and purpose to Fridays.

* And to the 62 xenopus laevis, 30 Bufe marinus, 28 Rana pipiens, and 2 Bufe alvarius who gave up their 
precious bodily fluids over the course of this research. Thanks, guys!

Above all, my deepest gratitude to Mary -- sometimes my conscience, always my friend, my ally, and more... 
TABLE OF CONTENTS

PAGE

ACKNOWLEDGEMENTS . . . . . . . . . . . . . . iii

LIST OF TABLES . . . . . . . . . . . . . . vii

LIST OF FIGURES . . . . . . . . . . . . . . viii

GENERAL INTRODUCTION . . . . . . . . . . . . I 1

CHAPTER I

THE EFFECTS OF ADRENERGIC BLOCRADE

ON DEHYDRATION TOLERANCE IN

XENQPUS LAEYIS

Introduction . . . . . . . . . 7

Materials and Methods . . . . . . . 9

Results . . . . . . . . . . 10

Discussion ........... 10

CHAPTER II

AN ASSAY FOR CATHEPSIN ACTIVITY

IN TOAD PLASMA

Introduction . . . . . . . . 16

Classification . . . . . . 16

Physiological and

Pathological Functions . . $2 \emptyset$

Assay Techniques . . . . . . 23

Materials and Methods . . . . . . 25

"Shock" Plasma . . . . . . . 25

Hemoglobin Solution . . . . . 26 
PAGE

Chemical Determinations . . . 26 Results ............ . . 29

Discussion . . . . . . . . . 43

CHAPTER III

DEHYDRATION AND CIRCULATORY SHOCK

IN BUFO MARINUS

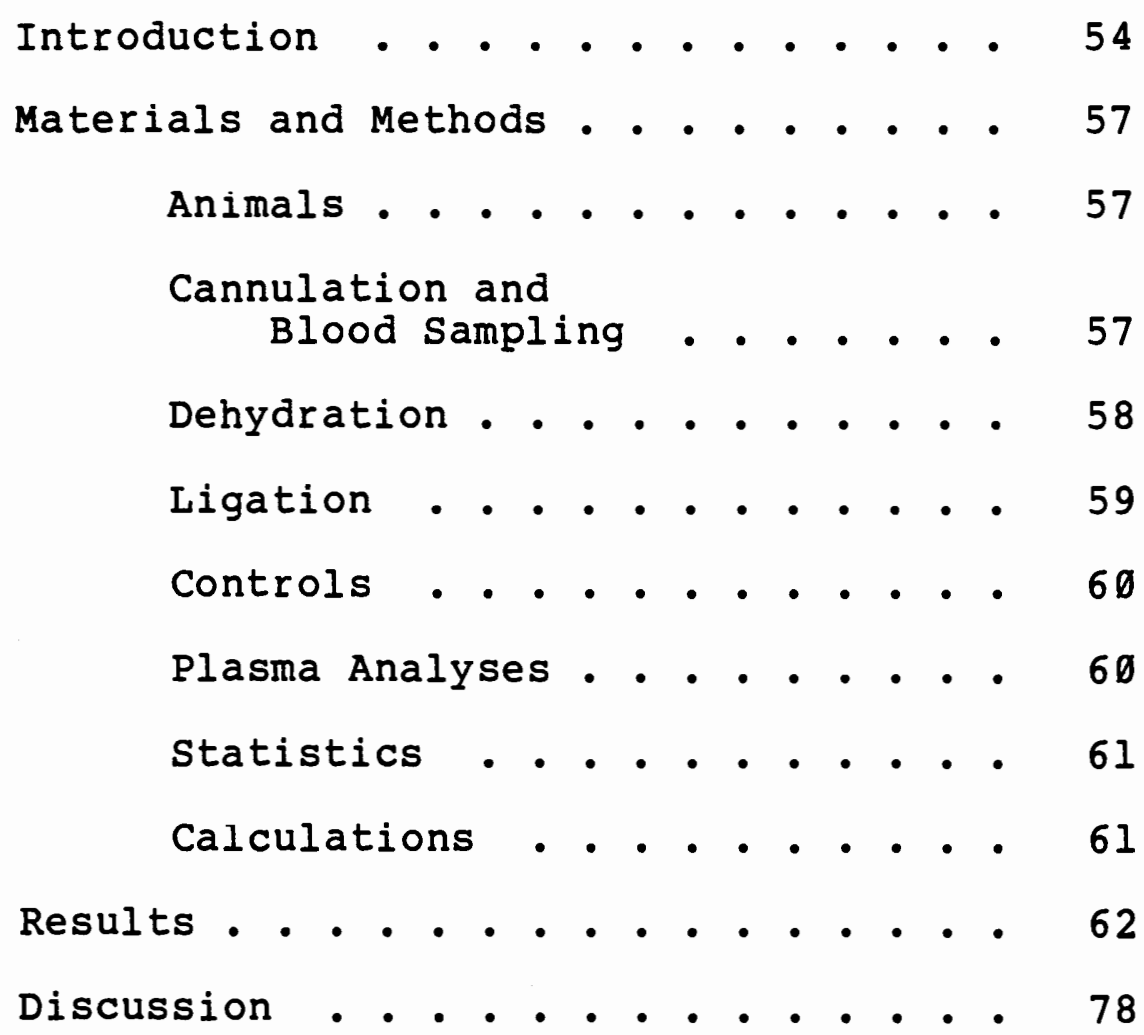

GENERAL DISCUSSION . . . . . . . . . . . 87

REFERENCES .................... 89 
LIST OF TABLES

TABLE

PAGE

I Water Loss at C.A.P., Expressed as Percent of

Original Body Mass, for Control and

Pharmacologically-Treated Xenopus laeyis. •

II Classification of the Cathepsins . . . . . . 17

III Plasma-Dependent Cathepsin Activity With and

Without Cysteine Near $\mathrm{pH} 3.0$. . . . . . $4 \emptyset$

IV Time Required to Reach Various Stages

of Dehydration . . . . . . . . . 63

V Plasma Sodium Concentrations . . . . . . . 64

VI Plasma Potassium Concentrations . . . . . 67

VII Hematocrit . . . . . . . . . . 68

VIII Plasma Protein Concentrations . . . . . $7 \emptyset$

IX Inltial Plasma Cathepsin Activity

and Body Mass ............. . 71

$x$ Plasma Cathepsin Activity Relative to

24 Hours Post-Surgery . . . . . . . . 73

XI Absolute Plasma Cathepsin Activity

Relative to 24 Hours Post-Surgery . . . . 76

XII Plasma Cathepsin Activity Relative to

Immediately Post-Surgery . . . . . . 77 


\section{LIST OF FIGURES}

F IGURE

PAGE

1. The relationship between net absorbance at $280 \mathrm{~nm}$ and the final $\mathrm{pH}$ of the assay mixture without cysteine in experiments conducted with toad plasma (closed circles) and tap water (open circles). . . . . . . $3 \emptyset$

2. The estimated difference in net absorbance at $280 \mathrm{~nm}$ between results using toad plasma and tap water in the cysteinefree assay (closed triangles) as compared to actual net absorbance at $280 \mathrm{~nm}$ in the plasma vs. saline assay (open triangles). The line was drawn for ease of comparison only . . . . 32

3. The relationship between net absorbance at $280 \mathrm{~nm}$ and the final $\mathrm{pH}$ of the assay mixture with cysteine in experiments conducted with toad plasma (closed circles) and tap water (open circles). . . . . . 35

4. The estimated difference in net absorbance at $280 \mathrm{~nm}$ between results using toad 
PAGE

plasma and tap water in the sulfhydryl assay (closed triangles) as compared to actual net absorbance at $280 \mathrm{~nm}$ in the plasma vs. saline assay (open triangles). The line was drawn for ease of comparison only . . . . . . . . 38

5. Net absorbance at $280 \mathrm{~nm}$ as a function of time of incubation of the assay mixture at $37^{\circ} \mathrm{C}$. The points represent the results of individual assays; the line was produced by least-squares linear regression using the data at 6,12 , and 18 hours. . . . . . . . . .

6. Net absorbance at $280 \mathrm{~nm}$ as a function of the volume of toad plasma used in the assay. The points represent the results of individual assays; the line was produced by least-squares linear regression

7. Mean plasma sodium concentrations for all three treatment groups as related to elapsed time following cannulation. The lines represent \pm two standard errors of the mean. Dehydration times are also mean values (see Table IV) . 
PAGE

8. Plasma cathepsin activity relative to 24

hours after cannulation. Lines connect

results from the same individual.

Single values for dehydrated toads are

represented as unconnected triangles. 


\section{GENERAL INTRODUCTION}

Amphibians are highly susceptible to dehydration in terrestrial environments. Evaporative water loss from most amphibians occurs at about the same rate as from a free surface of water and they cannot produce urine hyperosmotic to their body fluids (Bentley, 1971). Adaptation to terrestrial environments in amphibians does not usually involve mechanisms to reduce water loss, but rather increased tolerance to water loss. Among anuran amphibians (frogs and toads) there is a general positive correlation between dehydration tolerance and the terrestriality of the species (Thorson and Svihla, 1943; Thorson, 1955).

The physiological basis of dehydration tolerance is presently unclear. A detailed understanding of the nature of dehydrational death is essential to determining the mechanisms of extended tolerance. As in any complex system, the component or components that fail first are the most critical to the continued functioning of the system.

The principal hypothesis as to the immediate cause of dehydrational death in anurans is that of cardiovascular failure leading to a curtailment of circulatory oxygen delivery and generalized anoxia (Shoemaker, 1964; Hillman, 1978b). It is not entirely clear, however, exactly how dehydration leads to this cardiovascular debilitation. 
Dehydration has been shown to cause a significant reduction in circulating plasma volume in a variety of amphibians. However, the proportion of water lost from the plasma as compared to the whole animal varies greatly among species. The tiger salamander (Ambystoma tigrinum) loses plasma water with dehydration just as predicted from the overall water deficit (Alvarado, 1972), while the blood of Rana pipiens has a percent water loss that is almost twice that of the frog as a whole (Smith and Jackson, 1931). The importance of the maintenance of plasma volume to dehydration tolerance in amphibians has not been systematically examined, although in mammals it is thought to be a critical aspect of the relative ability to withstand desiccation (Schmidt-Nielsen, 1964).

Hypovolemia is but one consequence of dehydration in amphibians. With loss of water, there is a proportional increase in the non-permeant osmotic concentration and hematocrit of the blood. Plasma hyperosmolality has been implicated as a limiting factor in dehydrational death in anurans (Hillman, 1978b; 1980), and the increasing viscosity that accompanies rising hematocrit has been shown to further compromise cardiovascular function (Hillman, 1978b). However, nothing is known about the role of hypovolemia itself in dehydrational death in anurans.

This study was undertaken to investigate the possible importance of hypovolemia in dehydrational death and, 
conversely, the significance of plasma volume maintenance to desiccation tolerance in anurans. Two approaches were taken: (1) interference with the normal compensatory mechanisms for reduced blood volume in order to determine their contribution to dehydration tolerance, and (2) assessment of the consequences of dehydration relative to hypovolemia and the possibility of circulatory shock.

If hypovolemia is an important factor in dehydrational death in anurans, then the normal physiological mechanisms that compensate for reduced blood volume should be critical for survival. Interference with these mechanisms should significantly reduce desiccation tolerance. The importance of sympathetic reflex compensation for hypovolemia in mammals is well known (Chien, 1967). The possible importance of sympathetic compensation in anurans is the subject of Chapter I.

If hypovolemia is the cause of the circulatory collapse that precedes death in dehydration (Shoemaker, 1964), then there should be some indication of circulatory shock. Shock is a generalized insufficiency of blood flow to such a degree that extensive tissue damage results from inadequate oxygen delivery (Guyton, 1981). Dehydrational death in anurans is associated with such a generalized anoxia (Hillman, 1978b), but circulatory shock has never been demonstrated in amphibians. 
Any condition which reduces cardiac output may result in circulatory shock in mammals (Guyton, 1981) and over one hundred different types of shock have been described (Hardaway, 1981). Causes of shock include damage to the heart as in myocardial infarction (cardiogenic shock), massive allergic reaction (anaphylactic shock), bacterial infection (septic shock), serious physical trauma (traumatic shock), and neurological damage or anesthesia (neurogenic shock). The best known type is hypovolemic shock, in which reduced blood volume results in a decrease in venous return to the heart and a fall in cardiac output. The most important cause of hypovolemia, from a medical standpoint, is loss of blood (hemorrhagic shock), although dehydration can lead to a similar shock state (Guyton, 1981).

Shock may be divided into three distinct phases (Guyton, 1981): non-progressive, progressive, and irreversible. Non-progressive or compensated shock is characterized by an assortment of negative-feedback physiological responses that serve to maintain arterial pressure and restore blood volume. The sympathetic nervous system is of particular importance in cardiovascular adjustments at this stage (Chien, 1967; see Chapter I). With time or further loss of blood volume, shock may enter the second phase, called progressive or decompensated shock, characterized by the predominance of positive-feedback mechanisms that accelerate cardiovascular failure. The 
compensatory mechanisms begin to fail in severe shock and an ever-increasing cycle of circulatory deterioration is initiated: shock causes damage to the cardiovascular system, which worsens the shock state, leading to further damage, and so on. Eventually, so much damage has been done to the cardiovascular system that death becomes inevitable. Arterial pressure and cardiac output may be temporarily restored to near normal levels but no type of therapy can prevent death (Guyton, 1981). It is likely that deterioration of the heart is the reason for the irreversibility of this final stage of shock (Crowell and Guyton, 1962; Guyton, 1981), although collapse of the peripheral vasoconstriction is an alternative hypothesis (Bond et ąl., 1973).

One positive-feedback mechanism in progressive shock is believed to be a consequence of prolonged sympathetic stimulation. Tissues made ischemic by the intense vasoconstriction seen in shock may become necrotic and release toxic substances into the circulation. of particular importance is a myocardial depressant factor (MDF) produced by the ischemic pancreas (Lefer, 1978). Vasoconstriction in the splanchnic circulation produces hypoxia in the pancreas and hypoxia promotes the breakdown of lysosomal membranes in pancreatic cells (Lefer, 1978), apparently by promoting $\mathrm{Ca}^{2+}$ influx into the cells (Hock et al., 1984; Lefer and Papanicolaou, 1985). Lysosomal 
disruption releases a variety of proteolytic enzymes called cathepsins (Glenn and Lefer, 1971). One or more of these cathepsins cleaves a plasma protein substrate to produce

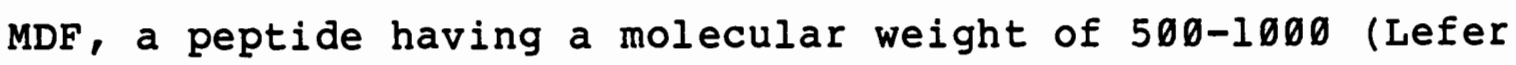
and Martin, 197ø; Lefer and Barenholz, 1972; Leffler et al., 1973; Litvin et al., 1973). In the circulation, MDF depresses cardiac contractility by 50-80\%, thus further reducing pancreatic blood flow and accelerating MDF formation (Lefer et al., 1967; Lefer and Blattberg, 1968; Leter, 1970). MDF also specifically constricts splanchnic (superior mesenteric) arterial strips but not aortic strips (Glucksman and Lefer, 1971) and depresses its own clearance from the blood (Lefer and Blattberg, 1968).

Plasma cathepsin activity has been used previously as an indicator of the degree of circulatory shock in experimental animals (Curtis and Lefer, 1980), but never in amphibians. Chapter II of this thesis describes the development of an assay for cathepsin activity in toad plasma and Chapter III concerns the application of that assay to determine whether or not toads suffer from circulatory shock as a result of dehydration. 
CHAPTER I

\section{THE EFFECTS OF ADRENERGIC BLOCKADE ON DEHYDRATION TOLERANCE IN \\ XENOPUS LAEVIS}

\section{INTRODUCTION}

The role of the sympathetic nervous system in hypovolemia has been well documented in mammals (see Chien, 1967). A reduction in blood volume results in a fall in blood pressure which is detected by baroreceptors in the carotid arteries and aortic arch. Blood pressure is regulated by the medullary cardiovascular center via sympathetic nerves to the heart and blood vessels and catecholamines from the adrenal medulla. Reflex activation of the sympathetic nervous system with falling pressure results in (I) an increase in heart rate and force of contraction to maintain cardiac output and (2) selective vasoconstriction to redistribute the remaining blood to vital areas and to increase total peripheral resistance. Thus, sympathetic activation is an emergency response to maintain central arterial pressure and circulation to the heart and brain.

There is some evidence for sympathetic involvement in the response to dehydrational hypovolemia in anurans. Sympathetic reflexes have been implicated in the maintenance 
of blood pressure (Sham et al., 1984), the redistribution of blood flow (Hillman and sommerfeldt, 1981), and the hydroosmotic (water uptake) response (Yokota and Hillman, 1984) in a number of anuran species. It should be possible to reduce dehydration tolerance using adrenergic blocking agents if adrenergically-mediated adjustments to hypovolemia are important to survival in dehydration. In addition, since cardiac adrenoceptors in amphibians are of the $\beta$-type (Erlij et al., 1965; Stene-Larsen and Helle, 1978; Ask, 1983; Herman and Sandoval, 1983), while vascular adrenoceptors are predominantly of the $\alpha$-type (Erlij et al., 1965; Herman and Sandoval, 1983), it should also be possible to examine separately the relative importance of changes in cardiac performance and peripheral vasoconstriction to desiccation tolerance.

In this experiment, Xenopus laevis treated with propranolol (a non-specific $\beta$-blocker) or phenoxybenzamine (an $\alpha,-$-blocker) and control frogs were dehydrated to determine the effects of selective adrenergic blockade on survival. Xenopus is particularly suited to this type of study because of its relatively low dehydration tolerance, insignificant bladder volume, and lack of any hydroosmotic response (Hillman, 1978a). Also, much is known about the physiological consequences of dehydration in this species (Hillman, 1978a; 1978b; 1980; Hillman and Sommerfeldt, 1981) . 
MATERIALS AND METHODS

Xenopus laevis were purchased from commercial suppliers. The frogs were maintained in tap water at room temperature and fed weekly with a ground liver preparation. Animals used in experimentation had a mean mass of $16.8 \mathrm{~g}$ ( $\mathrm{SE}=1.1 \mathrm{~g}$; range 9.1-31.0 $\mathrm{g}, \mathrm{N}=39$ ).

The frogs were blotted and placed in pre-weighed 1-pint plastic freezer containers that had ventilation holes bored in the lids. Body mass was measured to the nearest $0.1 \mathrm{~g}$ by weighing the container and frog together and subtracting the mass of the container. Animals could thus be weighed without handling them. Dehydration took place at room temperature with no attempt to control humidity. The frogs were weighed periodically until an average loss of 20-258 of original body mass was achieved. They were then divided into three groups of approximately equal mean mass. Control animals were injected with 0.98 saline; experimental animals received either $1 \mathrm{mg} / \mathrm{kg}$ DL-propranolol (Sigma) or $10 \mathrm{mg} / \mathrm{kg}$ phenoxybenzamine. The volume used in all cases was $\emptyset .1 \mathrm{ml}$, and the solutions were introduced by injection into the dorsal lymph sac. The frogs were then weighed periodically until they died. The criterion of death used in this study was the critical activity point (CAP), defined as the point at which a frog is unable to right when flipped on its back (Hillman, 1978b). 
Mean water loss at CAP, expressed as percent of original body mass, was compared for the three groups by analysis of variance. In addition, the control and propranolol group means were compared with a two-tailed t-test. A $P<\emptyset .05$ was considered significant.

\section{RESULTS}

The results are presented in Table I. Frogs injected with propranolol or phenoxybenzamine reached CAP having lost less water, on the average, than untreated animals, al though analysis of variance showed no significant difference between the means of the three groups $(P=\emptyset .13)$. If, however, the phenoxybenzamine data is ignored and the control and propranolol group means are compared using a two-tailed t-test, then the difference between these two means is statistically significant $(P<\emptyset . \emptyset 5)$.

\section{DISCUSSION}

The mean water loss at critical activity point (CAP) reported here for control xenopus ( 36.18 original body mass) is greater than the value of $33.8 \%$ reported for Xenopus by Hillman $(1978 \mathrm{~b} ; 1980)$. Frogs used in the present study were considerably smaller than those used by Hillman, however, and tolerance to water loss appears to be greater for frogs 


$$
z 1 m m m
$$

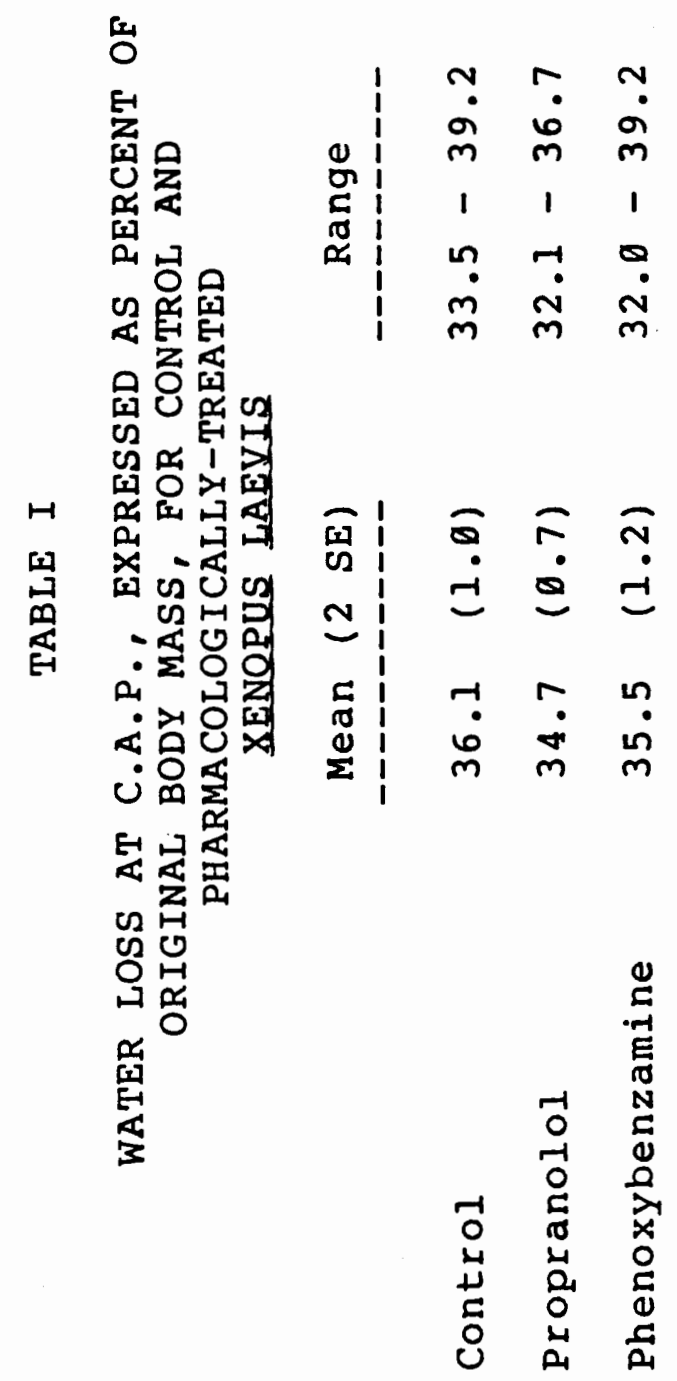


of lower body mass (Thorson, 1955). The frogs in the present study lost water at a rate of $10-308$ original body mass per day, as opposed to the 6-98 Hillman reported.

The results of the pharmacological treatments are inconclusive. Statistically, the reduction in dehydration tolerance brought about by adrenergic blockade is not significant (by ANOVA). However, there is an indication that $\beta$-adrenergic blockade with propranolol may interfere slightly with adjustments to hypovolemia (see t-test results). It must be stressed that it is not statistically appropriate to use a t-test to test the difference between two means within a group of three. Still, it is possible that a much larger data base would provide evidence that the effects of propranolol are real.

Drug concentrations used in this study were within the range of those used in previous experiments with amphibians. Hillman (1982) found that dosages of propranolol in excess of $\emptyset . \emptyset 1 \mathrm{mg} / \mathrm{kg}$ produced a significant reduction in maximal heart rate in scaphiopus intermontanus. Lillo (1979) reported that $2 \mathrm{mg} / \mathrm{kg}$ propranolol caused a long-lasting bradycardia in Rana catesbeiana. Yokota and Hillman (1984) used $2.5 \mathrm{mg} / \mathrm{kg}$ propranolol and $12.5 \mathrm{mg} / \mathrm{kg}$ phenoxybenzamine in dehydrated Bufe cegnatus, although no effect of the $\alpha$-blocker could be seen in their results. Phenoxybenzamine has been shown to block vasoconstriction by catecholamines in vitce in isolated artery strips from Bufe marinus (Rirby 
and Burnstock, 1969a) and to block the in vive pressor response to catecholamines in Rana pipiens (Erlij et al., 1965) and Bufe marinus (at $2 \mathrm{mg} / \mathrm{kg}$; Kirby and Burnstock, 1969b). In trials prior to this study, $1 \mathrm{mg} / \mathrm{kg}$ propranolol was found to depress maximal heart rate in Xenopus, completely abolishing exercise tachycardia in some cases. Both degree and duration of effects were variable, however. No attempt was made to confirm the effectiveness of $\alpha$-blockade during these experiments.

The relative importance of cardiac $(\beta)$ and peripheral $(\alpha)$ factors in prolonged hypovolemia and circulatory shock remains controversial, even in mammals. Although heart rate and force of contraction certainly increase under sympathetic stimulation (Chien, 1967), the actual effect on cardiac output may be minor. Ushioda et all. (1983) found no significant difference in cardiac output between $\beta$-adrenergically blocked and $\beta$-intact sheep with hemorrhage. Apparently the increase in heart rate is offset by a decline in ventricular filling time and stroke volume, despite the positive inotropic effect of adrenergic stimulation. Peripherally, sympathetic vasoconstriction, while maintaining blood pressure and flow to the heart and brain, may lead to widespread tissue ischemia and the release of toxic products, including a myocardial depressant factor (MDF; Lefer, 1978). For this reason, $\alpha$-adrenergic antagonists are often used in addition to volume replacement 
in the treatment of circulatory shock (Chien, 1967; Guyton, 1981). Thus, in the present experiments with Xenopus, $\beta$-blockade may have had no effect on cardiac output and $\alpha$-blockade without volume replacement may have had both beneficial and detrimental effects.

Assuming the adrenergic blockers did interfere significantly with sympathetic reflex compensation in hypovolemia, it is quite likely that this would have little apparent impact on mean water loss at CAP. Hillman (1978b) showed that maximal oxygen consumption rate (VO2 max) declines with dehydration in Xenopus, and that CAP is the point at which V02 max falls below resting metablolic demand. At this point, circulatory oxygen delivery is no longer adequate to satisfy minimal requirements and $a$ generalized tissue anoxia ensues. However, the decline in V02 $\max$ is not linear. At $20 \%$ dehydration, VO2 max is still 708 of the value for hydrated Xenopus, reflecting a considerable aerobic scope. Water loss in excess of 208 original body mass causes a rapid fall in VO2 max to CAP. Thus, measured as the curtailment of oxygen delivery to metabolizing tissues, well over half the cardiovascular debilitation caused by dehydration occurs with the last 10-158 water loss. In this range, the slope of the relationship between $\mathrm{VO} 2 \max$ and water loss is so steep that factors which significantly affect circulatory oxygen transport may have no measurable effect on mean water loss 
at CAP. Therefore, the present experimental design may not be sufficiently sensitive to detect the effects of sympathetic blockade on adjustments to hypovolemia.

There is evidence that the sympathetic nervous system does indeed play a role in the response to hypovolemia in anurans. Sympathetic activation in mammals is characterized by tachycardia and an increase in the force of contraction of the heart and by selective vasoconstriction to maintain blood pressure and redistribute blood to vital areas (Chien, 1967). Dehydrated Xenopus show both an increase in resting heart rate (Hillman, 1978b) and a redistribution of systemic blood flow to the head at the expense of other regions (Hillman and Sommerfeldt, 1981). Mean arterial pressure in Rana catesbeiana is unaffected by two days under desiccating conditions but is significantly lower in dehydrated bullfrogs treated with the $\alpha$-blocker phentolamine (Sham et al., 1984). Each of these responses to dehydration in anurans is consistent with the results of sympathetic activation in mammals. In addition, Yokota and Hillman (1984) demonstrated $\beta$-adrenergic involvement in the cutaneous water balance response of Bufe cegnatus, which is important in rehydration following hypovolemia. 


\section{CHAPTER II}

\section{AN ASSAY FOR CATHEPSIN ACTIVITY \\ IN TOAD PLASMA}

\section{INTRODUCTION}

The term "cathepsin" (from the Greek meaning "to digest") was first applied in 1929 to tissue proteinase activity at acid pH (Mycek, 197ø). Work in the 193øs was conducted under the assumption that this activity was due to a single enzyme. However, the use of synthetic peptide substrates clearly demonstrated more than one type of proteolytic activity in "cathepsin" preparations, including activity under less acidic and even neutral conditions. Since 1941, at least 19 different enzymes have been designated "cathepsins" (see Table II). The term is now essentially synonymous with "intracellular proteinase" (Barrett, 1980). With few exceptions (cathepsins $F$ and $R$ ), these have proven to be lysosomal enzymes.

\section{Classification}

At present, proteinases in general are classified on the basis of catalytic mechanism, and this is the scheme used in Table II to organize the cathepsins (Barrett, 1975; 1980). Endopeptidases hydrolyze proteins to produce shorter peptides, primarily by cleaving bonds away from the ends of 


\section{TABLE II}

CLASSIFICATION OF THE CATHEPSINS

\section{Endopeptidases}

Aspartic

(=Carboxyl)

D

E

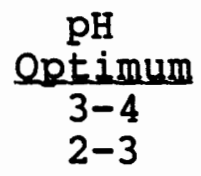

Serine

G

$\mathbf{R}$

$$
\begin{gathered}
7 \cdot 5-8 \\
7+
\end{gathered}
$$

Cysteine

(=Thiol)

$\begin{array}{lc}\text { Bl } & 4-6 \\ \text { H } & 5-7 \\ \text { J } & 6-7 \\ \text { K } & 6-7 \\ \text { L } & 5-5.5 \\ \text { M } & 5-7 \\ \text { N } & 3-6 \\ \text { P } & 5-6 \\ \text { S } & 3 \\ \text { T } & 6-7\end{array}$

Unknown

F

4.5

Exopeptidases

Carboxypeptidases

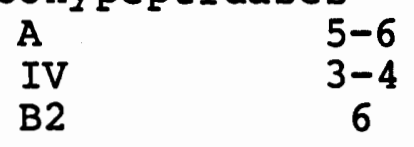

Dipeptidylpeptidase
Taylor and Tappel, 1974

Greenbaum and Sherman, 1962

Lones and Singh, 1980

McDonald et al., 1969 
the polypeptide chains. Exopeptidases act at the free amino or carboxyl termini of proteins or peptides and remove one or two amino acid residues sequentially. Because the action of endopeptidases would free more termini for attack by exopeptidases, the two types of enzymes are believed to act in concert in the lysosomal hydrolysis of proteins, as shown by Goettlich-Riemann et al. (1971) using hemoglobin as substrate. The endopeptidases generally have lower specific activities and are regarded as rate limiting in this process (Bohley et al., 1971). However, purified exopeptidases show little or no activity with protein substrates and are often not considered true proteinases.

The endopeptidases are further divided into four classes according to their mechanisms of hydrolysis: the aspartic, serine, cysteine, and metalloproteinases (Barrett, 1980). Peptide bond cleavage by proteolytic enzymes involves polarization of the bond by nucleophilic attack on the carbonyl carbon atom together with proton donation to the peptide nitrogen. Each class of endopeptidases is characterized by the amino acid residues that perform the nucleophile and proton donor functions (Neurath, 1984). In addition, some authorities recognize a fifth group which presently includes proteinases of unknown catalytic mechanism.

The aspartic proteinases were formerly called "acid" or "carboxyl" proteinases, since this class includes many 
enzymes active at low pH. Two carboxyl groups of aspartic acid residues are responsible for the activity of these enzymes. Pepsin and renin are examples of aspartic proteinases, as are cathepsins $D$ and $E$.

The serine proteinases make up the largest class of endopeptidases, numbering over 50 in mammals. Enzymes such as trypsin, chymotrypsin, thrombin, and cathepsins $G$ and $R$ all contain a reactive serine residue in their catalytic site. Serine proteinases are active only under neutral or slightly alkaline conditions.

Most of the cathepsins identified to date have been classified as cysteine or "thiol" endopeptidases (see Table II). These enzymes require the presence of sulfhydryl compounds (e.g., cysteine, mercaptoethylamine, or glutathione) for maximal activity, indicating the importance of the thiol group of a cysteine residue in the active site. Mammalian cathepsins $\mathrm{Bl}$ and $\mathrm{H}$ show a remarkable degree of sequence homology with papain, a plant cysteine endopeptidase, particularly in the region of the catalytic center (Takio et al., 1983). Because of their relatively broad activity against peptide bonds, Barrett and Kirschke (1981) consider the lysosomal cysteine proteinases as a group to be the most active proteinases in higher animals. None of the cathepsins is currently classified as a metalloproteinase, and only cathepsin F is considered a proteinase of unknown catalytic mechanism (Barrett, 1980). 
Physiological and Ratholegical Functions

Cathepsins perform a number of important physiological functions, ranging from the complete degradation of proteins to enzyme activation by the hydrolysis of specific peptide bonds. In discussing the evolution of proteases, Neurath (1984) proposed that such enzymes evolved from relatively non-specific digestive enzymes and have adapted to more complex regulatory tasks. Thus, the fundamental role of cathepsins is thought to be the breakdown of nonfunctional proteins (Lebez and Kopitar, 1970), the other functions having arisen in more advanced cells.

Protein degradation by cathepsins occurs intracellularly. The substrates include both endogenous cell proteins and exogenous proteins, such as collagen, fibrin, and several globulins, brought into the cell by some type of endocytosis (Barrett, 1978). Within the cell, cathepsins are generally confined to the lysosomal system, known to be the site of extensive protein hydrolysis (Coffey and DeDuve, 1968; Bohley et al., 1971). The wide range of $\mathrm{pH}$ optima among the cathepsins ( $\mathrm{pH} 2$ to 8 , see Table II) suggests that the intralysosomal pH may change sequentially from acidic to neutral or slightly alkaline to acidic, and so on. Such changes in $\mathrm{pH}$ have been shown to facilitate protein degradation by cathepsin mixtures in vitro (Goettlich-Riemann et al., 1971). The importance of these enzymes is demonstrated by their widespread distribution in 
organs and cells having phagocytic or proteolytic activity. Cathepsins have been identified in preparations of liver, spleen, kidney, pancreas, lung, thymus, placenta, skeletal muscle, bone marrow, and lymph nodes from several mammalian species and have been further localized in macrophages, lymphocytes, and leukocytes.

Some of the cathepsins are also known to participate in enzyme activation by the limited hydrolysis of precursor molecules. For example, bovine spleen cathepsin Bl catalyzes the production of trypsin from trypsinogen at pH 3.6 (Greenbaum and Sherman, 1962). Cathepsin G from human neutrophil lysosomes has been shown to convert angiotensin I to angiotensin II and also to cleave angiotensin II directly from a plasma protein precursor, both in the absence of renin, as part of a local pathway to regulate blood flow (Wintroub et al., 1984). Docherty et al. (1982) isolated an enzyme from the islets of Langerhans of rat pancreas that converts proinsulin to insulin at $\mathrm{pH}$ 5-6, and named it cathepsin $\mathrm{P}$.

Recently, a serine endopeptidase has been found associated with ribosomes in both prokaryotes and eukaryotes. It has been named cathepsin $R$ and is tightly bound to the $40 \mathrm{~S}$ subunit in eukaryotes (Levyant et al., 1979), mostly in a latent or "cryptic" state. Cathepsin R is believed to be responsible for the modification and 
cleavage of newly synthesized proteins and the excision of chains with translational errors (Levyant et all., 1976).

Because the uncontrolled release of proteolytic enzymes would be extremely dangerous to cells and tissues, the production and activity of cellular proteinases are tightly regulated. Only the inactive, higher molecular weight precursors of cathepsins are normally found in plasma and other extracellular fluids (zuehlsdorf et al., 1983). Activation of these precursors is regulated by limited proteolysis, and a variety of proteinase inhibitors exist in plasma to block or eliminate the active forms (Heimburger, 1975).

As a consequence of some pathological conditions, however, this regulation of cathepsin activity may break down. Many serious diseases involve excessive protein degradation. The wasting of muscle tissue in muscular dystrophy is thought to be caused by an unexplained increase in cathepsin $A$ and $D$ content in dystrophic muscle (Iodice et al., 1966). Pulmonary emphysema is apparently the result of proteolysis of the lung by cathepsin $G$ and elastase when the natural inhibitor of these enzymes is inactivated by smoke condensate (Nakajima et al., 1979). Cathepsins have also been linked to the production of a myocardial depressant factor (MDF) in circulatory shock, as described in the General Introduction. 
The vast majority of cathepsin research has dealt with the characteristics and functions of these enzymes in mammals. Even so, there there is evidence that cathepsins are present within lysosomes of all typical animal cells (Mellors, 1971). Cathepsin D, in particular, has been found in lysosomes of cells from protozoans to higher vertebrates (Barrett, 197ø). Very little work has been done on cathepsins in amphibians, however. Weber (1957) was able to link an unspecified "cathepsin" to the resorption of the tail in metamorphosing Xenopus larvae. This is apparently the only aspect of cathepsin activity, physiological or pathological, to have been examined in amphibians.

\section{Assay Techniques}

Many different assays have been developed for the determination of cathepsin activity in animal tissues. In general, an extract of the tissue in question is allowed to digest some substrate solution and the products of the reaction (amino acids or short peptides) are measured spectrophotometrically. The extent of the digestion is thus proportional to the amount of cathepsin activity in the tissue. Each cathepsin is usually assayed using a substrate toward which it is particularly reactive. With the development of synthetic substrates, it has become possible to design an assay for a single cathepsin. 
Plasma cathepsin D activity has been used previously to assess the role of lysosomal proteinases in circulatory shock. Curtis and Lefer (1980) measured cathepsin D activity in plasma of cats in hemorrhagic shock and were able to detect a ten-fold increase in activity over time. Cathepsin D activity has been shown to parallel myocardial depressant factor activity in subcellular fractions of incubated pancreas (Litvin et al., 1973). Cathepsin Bl may also be involved in the production of MDF. Litvin et al. (1973) found the optimal $\mathrm{pH}$ for MDF formation by pancreatic homogenates to be in the same range ( $\mathrm{pH} 5-6)$ as the optimum for cathepsin Bl activity. In addition, the same researchers showed that MDF production could be significantly reduced by the addition of p-chloromercuribenzoate ( $P C M B$ ) to the incubation medium. PCMB is a sulfhydryl reagent known to inhibit cathepsin Bl activity, but it is without effect against cathepsin $D$.

Cathepsin $D$ is relatively easy to assay. Although many different procedures have been devised, most researchers use a modified version of the method of Anson (1936). The assay used in the present work is essentially that of Mycek (1970), using hemoglobin as substrate. Published procedures, however, require purified or partially purified enzyme preparations. Thus, it was necessary to adapt the standard assay for use with unpurified toad plasma. 
Cathepsin Bl is usually assayed using a synthetic peptide substrate such as benzoyl-L-argininamide, but it may be assayed using hemoglobin if cysteine is added to the substrate solution (Mycek, 1970). Although not as specific for cathepsin $\mathrm{Bl}$, this method has the advantage of allowing direct comparison with cathepsin D activity on the same protein substrate.

The objectives of this chapter are: (1) to characterize the cathepsins present in shock plasma of toads by determining the relationship between plasma cathepsin activity and $\mathrm{pH}$ (with and without sulfhydryl activation), and (2) to develop a specific assay procedure for cathepsin activity in toad plasma.

\section{MATERIALS AND METHODS}

\section{"Sheck" Plasma}

In order to develop an assay for cathepsin activity in plasma, it was necessary to obtain blood from toads in circulatory distress or shock. Since the splanchnic region appears to be the major site of lysosomal damage and cathepsin release in circulatory shock (Glenn and Lefer, 1971), restriction of the blood supply to this region was used to induce a "shock" state. Toads (Bufo marinus) were anesthetized by partial immersion in a solution of tricaine methanesulfonate (MS-222), and the body cavity was opened by 
a lateral incision. Two ligatures were placed around the celiaco-mesenteric artery, thus blocking splanchnic blood flow, and the muscle and skin sutured closed. These toads were maintained with access to tap water for 1-3 weeks, at which point they were doubly pithed, and as much blood as possible was withdrawn from the exposed ventricle by heparinized syringe. The plasma was separated by centrifugation $(1000 \times \mathrm{g})$ and kept refrigerated or frozen until used. Plasma so obtained was consistently high in proteolytic activity.

\section{Hemoglobin solution}

A $2.58(w / v)$ hemoglobin solution was prepared by slowly dissolving $2.5 \mathrm{~g}$ bovine hemoglobin substrate powder (Sigma, Type II) per $100 \mathrm{ml}$ distilled water. To prevent bacterial growth, $2.5 \mathrm{ml}$ Merthiolate was added (Mycek, 1970). The solution was kept refrigerated until needed. Any volume not used within two weeks was discarded, since longer storage causes an increase in control absorbance (Takahashi and Tang, 1981).

\section{Chemical Determinations}

The relationship between plasma cathepsin activity and $\mathrm{pH}$ was determined over a broad $\mathrm{pH}$ range, both in the presence and absence of cysteine, a sulfhydryl activator. Sulfhydryl-independent activity was assayed with a substrate solution consisting of $4 \mathrm{ml}$ of the 2.58 hemoglobin 
solution, plus $2 \mathrm{ml}$ of a McIlvaine citrate-phosphate buffer at the appropriate $\mathrm{pH}$. This solution was allowed to equilibrate in a water bath at $37^{\circ} \mathrm{C}$ for 30 minutes. To initiate the reaction, $0.05 \mathrm{ml}$ shock plasma was added to $0.3 \mathrm{ml}$ of the substrate solution. The mixture was incubated at $37^{\circ} \mathrm{C}$ for 24 hours, at which point the reaction was terminated by the addition of $0.45 \mathrm{ml}$ of a $5 \%$ trichloroacetic acid (TCA) solution. After standing for 10 minutes at room temperature, the undigested hemoglobin precipitated by TCA was separated by centrifugation $(1000 \times \mathrm{g})$, and the clear supernatant was removed and centrifuged again. The absorbance at $280 \mathrm{~nm}$ of this second supernatant was determined spectrophotometrically. Duplicates were carried out for each sample, and the average value compared to the average of two controls in which TCA was added to the same substrate solution prior to the addition of the plasma. The net absorbance at $280 \mathrm{~nm}$ (experimental minus control) is thus a measure of plasma cathepsin activity. The effect of $\mathrm{pH}$ on this activity was determined by changing the $\mathrm{pH}$ of the buffer and therefore the final pH of the substrate solution as measured at $37^{\circ} \mathrm{C}$. Total activity, including sulfhydryl-dependent activity, was assayed in the same manner, except that the substrate solution consisted of $4 \mathrm{ml}$ of the 2.58 hemoglobin solution, $1 \mathrm{ml}$ citrate-phosphate buffer, and $1 \mathrm{ml}$ of $0.07 \mathrm{M}$ 
cysteine hydrochloride (adjusted to the $\mathrm{pH}$ of the buffer with $\mathrm{NaOH}$ ) .

Because the addition of cysteine to the assay appeared to promote proteolysis even in the controls, it was suspected that results obtained using cysteine might overestimate actual plasma cathepsin activity. To account for this "background" activity, the sulfhydryl assay was repeated, using tap water in place of the shock plasma. The difference between the net absorbance at $280 \mathrm{~nm}$ using plasma and that using tap water is the actual plasma-dependent activity.

To confirm this, and to confirm the existence of cathepsin B-type activity in shock plasma, a more direct comparison was made over the $\mathrm{pH}$ range $4 . \emptyset-7 . \emptyset$. In this experiment, plasma was added to the substrate solution with cysteine, as before, while in the controls an equal volume of $\emptyset .98 \mathrm{NaCl}$ was substituted for the plasma. No TCA was added to either set until the reaction was terminated 24 hours later.

To verify cathepsin D-type activity in shock plasma, both the tap water assay and the comparison of plasma and saline activities were then performed in the absence of cysteine over the $\mathrm{pH}$ range $3 \cdot \theta-6 . \emptyset$.

The sulfhydryl-free assay was used to assess the effects of time and volume of plasma used on the extent of the reaction. The relationship between the net absorbance 
at $280 \mathrm{~nm}$ and the time of incubation at $37^{\circ} \mathrm{C}$ was examined at $\mathrm{pH} 3.0$ in the absence of cysteine. The reaction was terminated after $6,12,18,24$, and 30 hours. Because this proved to be non-linear at the longer incubation times, the amounts of substrate solution and TCA used were doubled (to $0.6 \mathrm{ml}$ and $0.9 \mathrm{ml}$, respectively) in all further experiments. The relationship between the net absorbance at $280 \mathrm{~nm}$ and the volume of plasma used in the assay was determined (at $\mathrm{pH} 3 . \emptyset)$ for plasma samples from $\emptyset-\emptyset .5 \mathrm{ml}$, in $\emptyset .1 \mathrm{ml}$

increments. Least squares linear regressions were performed on the data from these two experiments.

\section{RESULTS}

The $\mathrm{pH}$ dependence of toad plasma cathepsin activity without cysteine is shown in Figure 1. The optimum pH for hemoglobin degradation was in the range of 2.5-3.2. Activity decreased sharply at higher $\mathrm{pH}$, and no activity at all was observed when the $\mathrm{pH}$ of the substrate solution exceeded 4.5. A final pH of 2.5 is the most acidic possible using this buffer.

There was a relatively small amount of "background" proteolytic activity, as shown by the results using tap water (Fig. 1), and this also disappeared above $\mathrm{pH} 4.5$. If the difference between the plasma and tap water curves is plotted as in Figure 2, a slightly different pH relationship 
Figure 1. The relationship between net absorbance at $28 \emptyset \mathrm{nm}$ and the final $\mathrm{pH}$ of the assay mixture without cysteine in experiments conducted with toad plasma (closed circles) and tap water (open circles). 


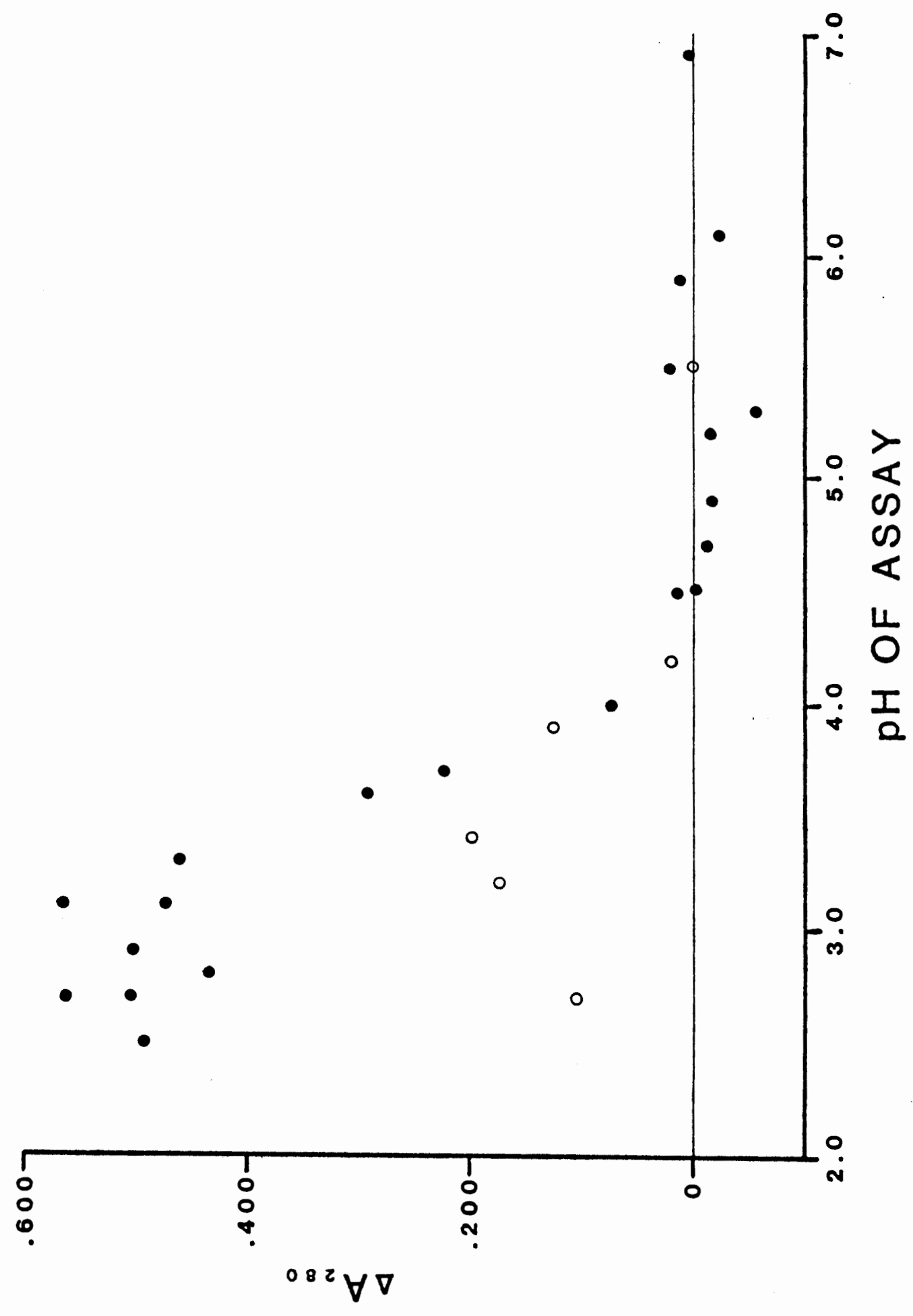


Figure 2. The estimated difference in net absorbance at $280 \mathrm{~nm}$ between results using toad plasma and tap water in the cysteine-free assay (closed triangles) as compared to actual net absorbance at $280 \mathrm{~nm}$ in the plasma vs. saline assay (open triangles). The line was drawn for ease of comparison only. 


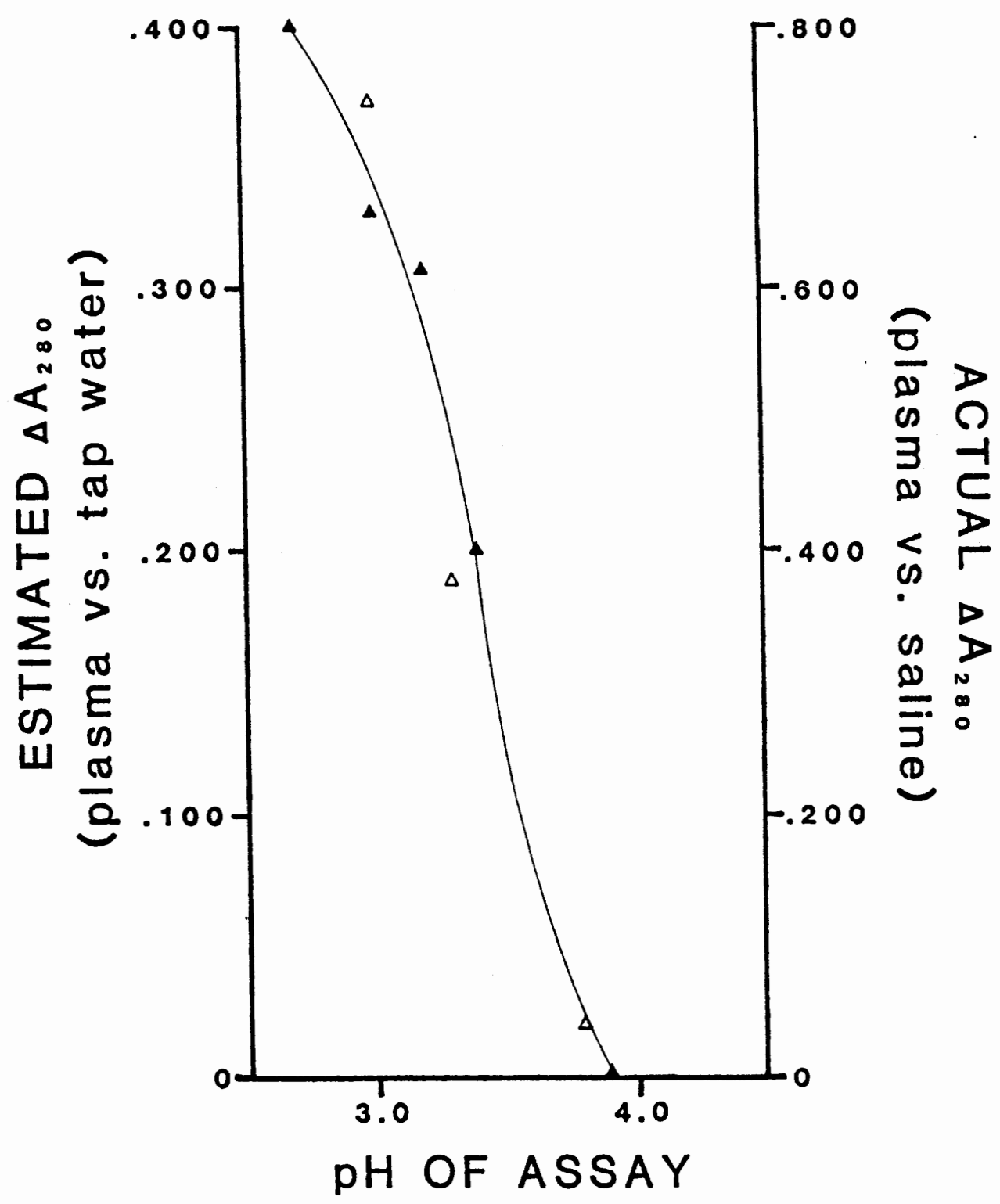


is obtained. Maximum hydrolysis occurs below $\mathrm{pH} 3 . \emptyset$, and no activity is seen above $\mathrm{pH} 3.9$. This same narrow $\mathrm{pH}$ range was apparent in the assay using saline as a control (Fig. 2).

The $\mathrm{pH}$ dependence of toad plasma cathepsin activity in the presence of cysteine is shown in Figure 3. Two peaks in net absorbance at $280 \mathrm{~nm}$ are apparent, one under acidic conditions and one nearer neutral pH. The former is very similar to the results seen without the sulfhydryl activator. The optimum pH for hemoglobin digestion was below 3.0 , and activity decreased rapidly between $\mathrm{pH} 3.0$ and 4. 0 . The second peak in plasma cathepsin activity with cysteine showed a $\mathrm{pH}$ optimum of 6.0 and was much broader than the first, even overlapping the more acidic peak at $\mathrm{pH} 4 \cdot y-4.5$. Assays conducted above $\mathrm{pH} 7.0$ gave erratic results.

When tap water was substituted for toad plasma in the sulfhydryl assay, the background proteolytic activity also appeared as two peaks (Fig. 3). The more acidic peak is virtually identical to the tap water curve seen without cysteine, except that the sulfhydryl activity was about 358 higher at its maximum ( $\mathrm{pH} 3.5)$. The second peak in background activity is much larger, with an optimum $\mathrm{pH}$ of 6.5. Thus, most of the "plasma cathepsin activity" seen in this $\mathrm{pH}$ range is not plasma-dependent. However, if the difference between the plasma and tap water curves for 
Figure 3. The relationship between net absorbance at $280 \mathrm{~nm}$ and the final $\mathrm{pH}$ of the assay mixture with cysteine in experiments conducted with toad plasma (closed circles) and tap water (open circles). 


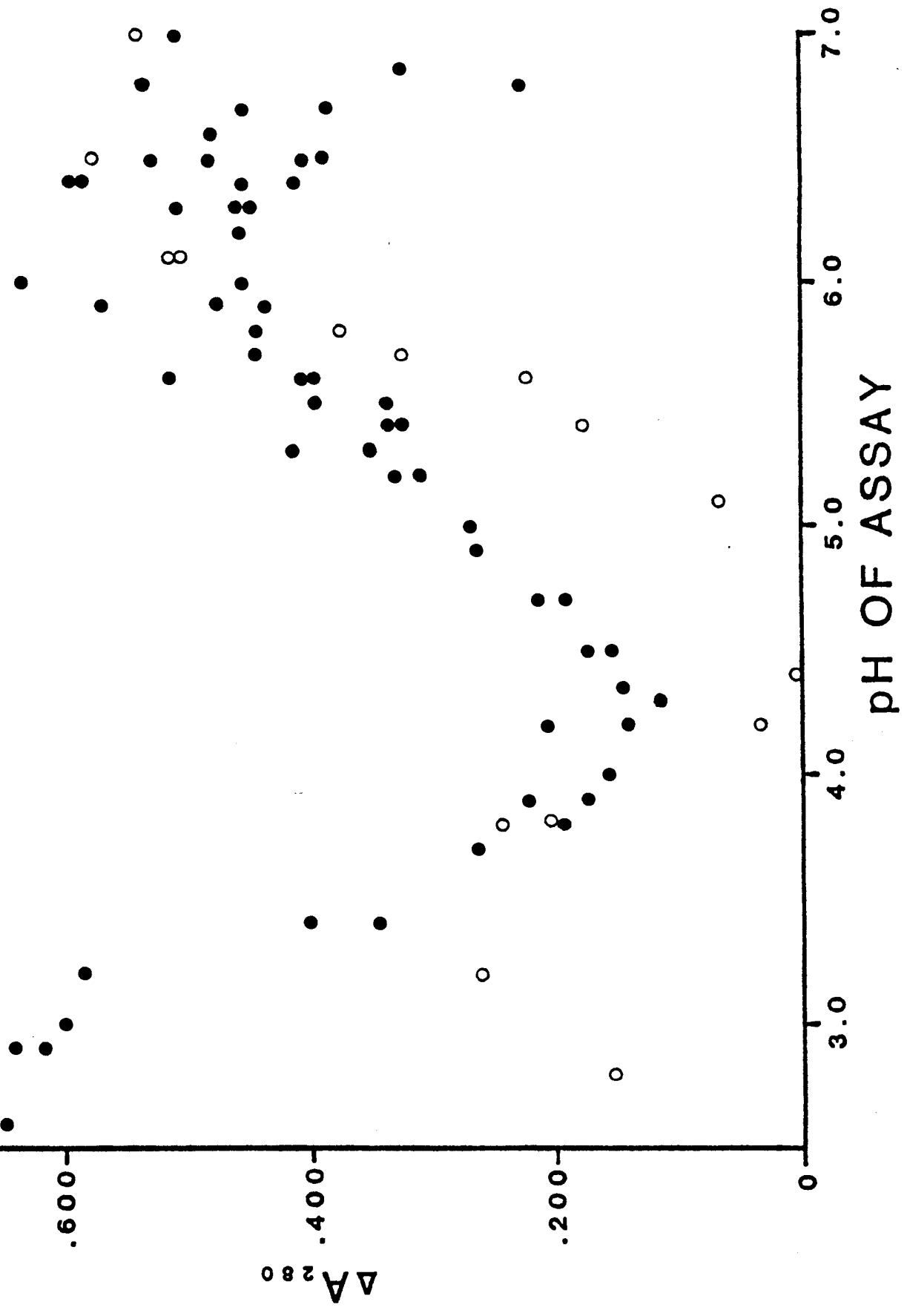


pH 4.ø-7. 0 is plotted as in Figure 4 , some activity remains and a very different $\mathrm{pH}$ relationship is obtained. The optimum $\mathrm{pH}$ is in the range 5.b-5.4, with little or no activity above pH 6.ø. The sulfhydryl assay using saline as a control gave similar results (Fig. 4 ).

Some limited comparisons were made using the same plasma in different assays. Plasma-dependent proteolytic activity near $\mathrm{pH} 3 . \emptyset$ was increased $10-208$ by the addition of cysteine to the substrate solution (Table III). The relationship between activity with cysteine at $\mathrm{pH} 3.0$ and $\mathrm{pH} 5 . \emptyset$ was too variable to draw any conclusions.

The relationship between net absorbance at $280 \mathrm{~nm}$ and time of incubation at $37^{\circ} \mathrm{C}$ is shown in Figure 5 , for assays conducted at pH 3.0 without cysteine. Activity increased linearly with reaction time to approximately 18 hours. Least squares linear regression using the data at 6,12 , and 18 hours produced a line $(r=\emptyset .99)$ having a $y$-intercept (net absorbance at zero time) of $\emptyset . \emptyset 84$. This agrees almost exactly with the result obtained when saline was substituted for plasma in the same assay at 24 hours (net absorbance $=\emptyset .083$ ), and therefore is a reasonable estimate of "zero activity."

Because the relationship between activity and reaction time was not linear at 24 hours, the volume of substrate solution used was doubled. With this adjustment, net absorbance at $280 \mathrm{~nm}$ was found to be positively correlated 
Eigure 4. The estimated difference in net absorbance at $280 \mathrm{~nm}$ between results using toad plasma and tap water in the sulfhydryl assay (closed triangles) as compared to actual net absorbance at $280 \mathrm{~nm}$ in the plasma vs. saline assay (open triangles). The line was drawn for ease of comparison only. 


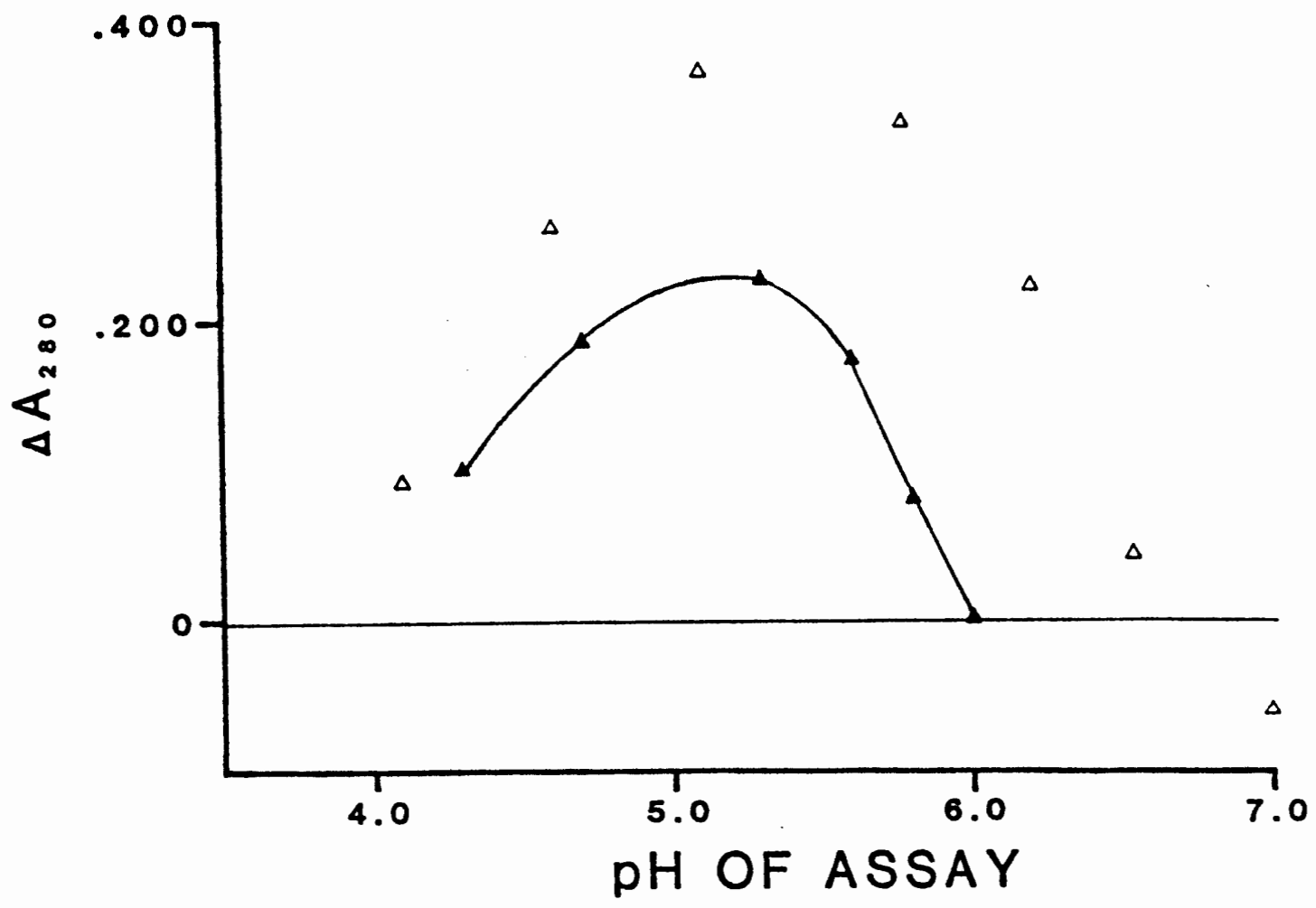




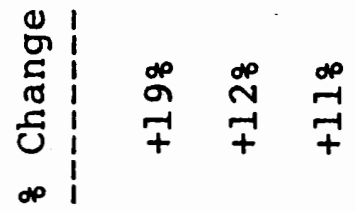

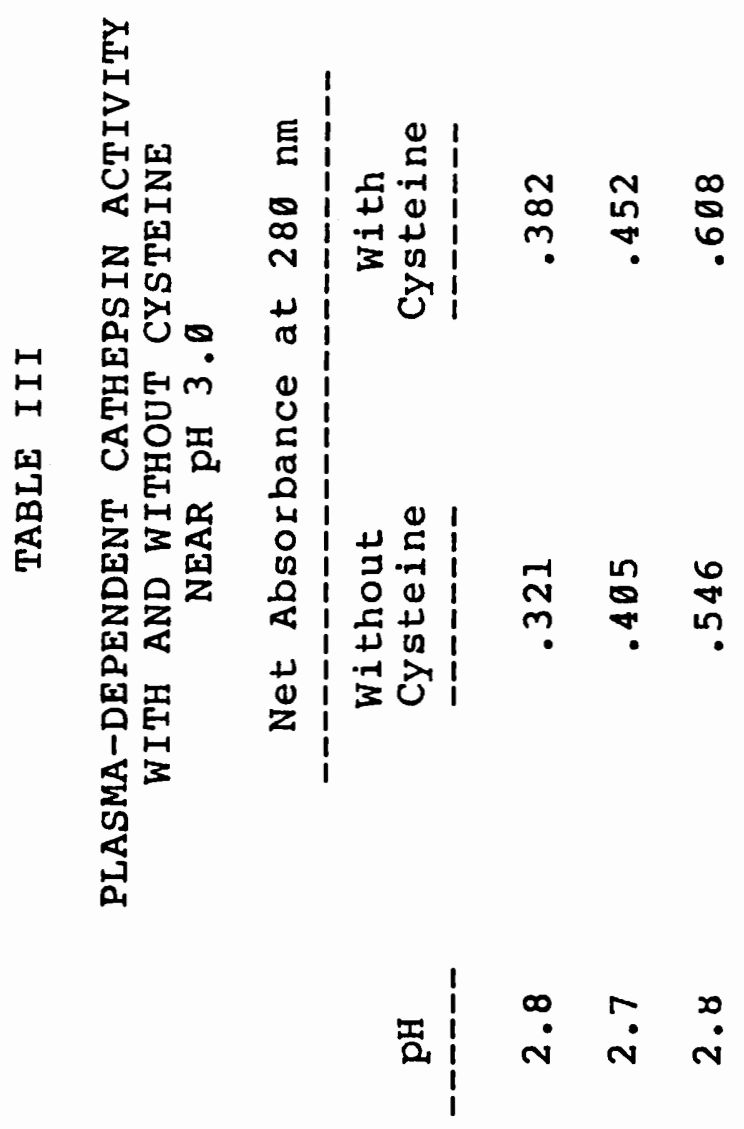


Figure 5. Net absorbance at $280 \mathrm{~nm}$ as a function of time of incubation of the assay mixture at $37^{\circ} \mathrm{C}$. The points represent the results of individual assays; the line was produced by least-squares linear regression using the data at 6,12 , and 18 hours. 


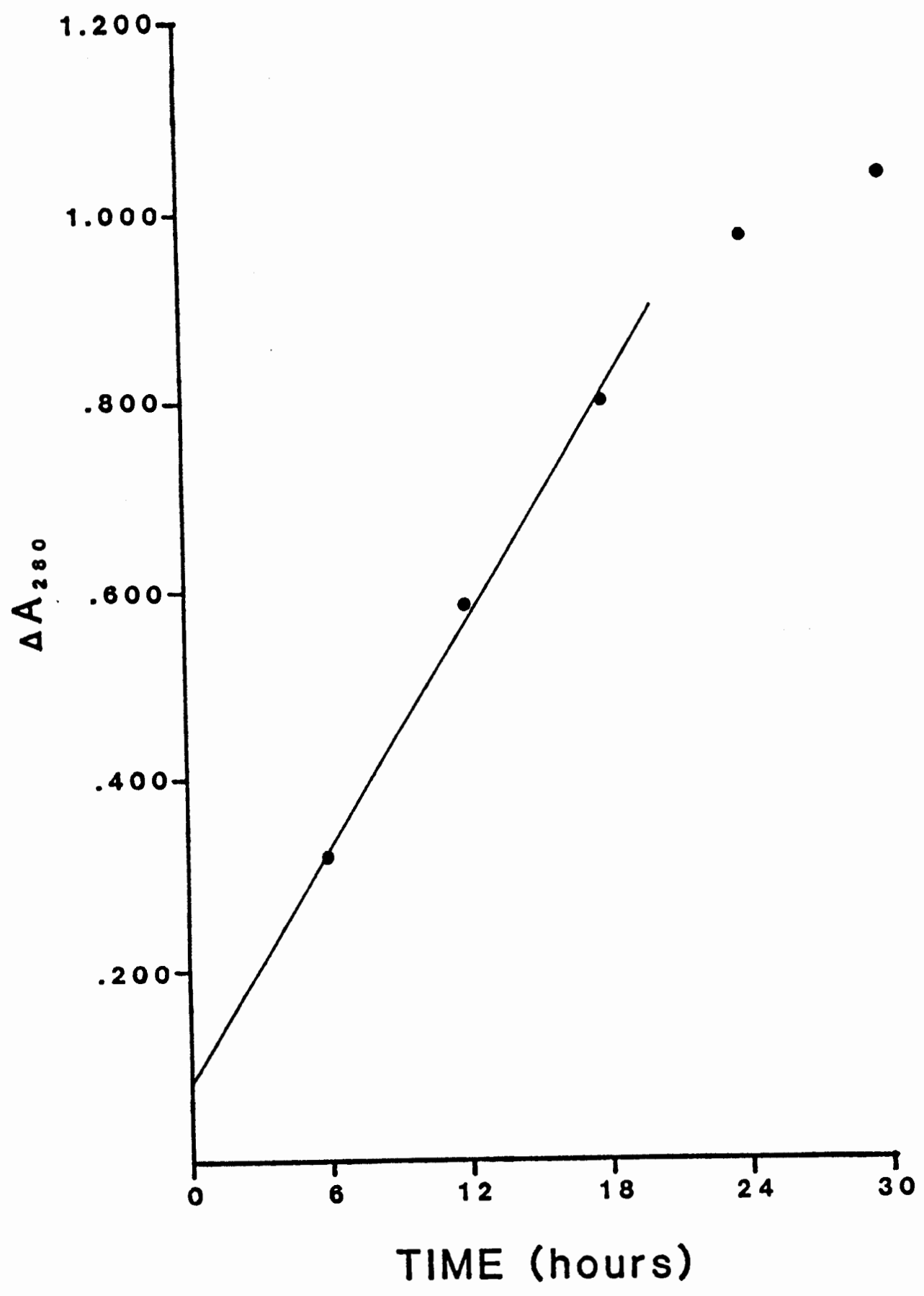


with the volume of plasma used in the assay $(r=\emptyset .99$, Figure 6). The $y$-intercept of the regression line for this data is 0.113 , representing zero plasma or "zero activity."

\section{DISCUSSION}

As stated previously, the assay used in this investigation is essentially that of Mycek (197ø). Two modifications of this procedure were necessary. First, the McIlvaine citrate-phosphate buffer was used because of its wide range of buffering capacity ( $\mathrm{pH} 2.2-8.0)$. This buffer has been used before in cathepsin assays (Taylor and Tappel, 1974; Shcherbak and Zhloba, 1979). Second, because no attempt was made to purify or concentrate the cathepsins in toad plasma, the time of incubation at $37^{\circ} \mathrm{C}$ was increased from 10 minutes to 24 hours. Increasing the reaction time is equivalent to increasing the amount of enzyme (Anson, 1936). Incubation times as long as 24 hours were common prior to Anson's work and have been used since in cathepsin assays (Goettlich-Riemann et al., 1971).

Certain cathepsins would not be detected by this assay and may be excluded from consideration. The exopeptidases do not readily digest protein substrates, and cathepsin $F$ has been shown to be without activity against hemoglobin (Lebez et al., 1971). The serine proteinases, cathepsins G and $\mathrm{R}$, have $\mathrm{pH}$ optima ( $7 . \varnothing$ and above) that are outside the 
Figure 6. Net absorbance at $280 \mathrm{~nm}$ as a function of the volume of toad plasma used in the assay. The points represent the results of individual assays; the line was produced by least-squares linear regression. 


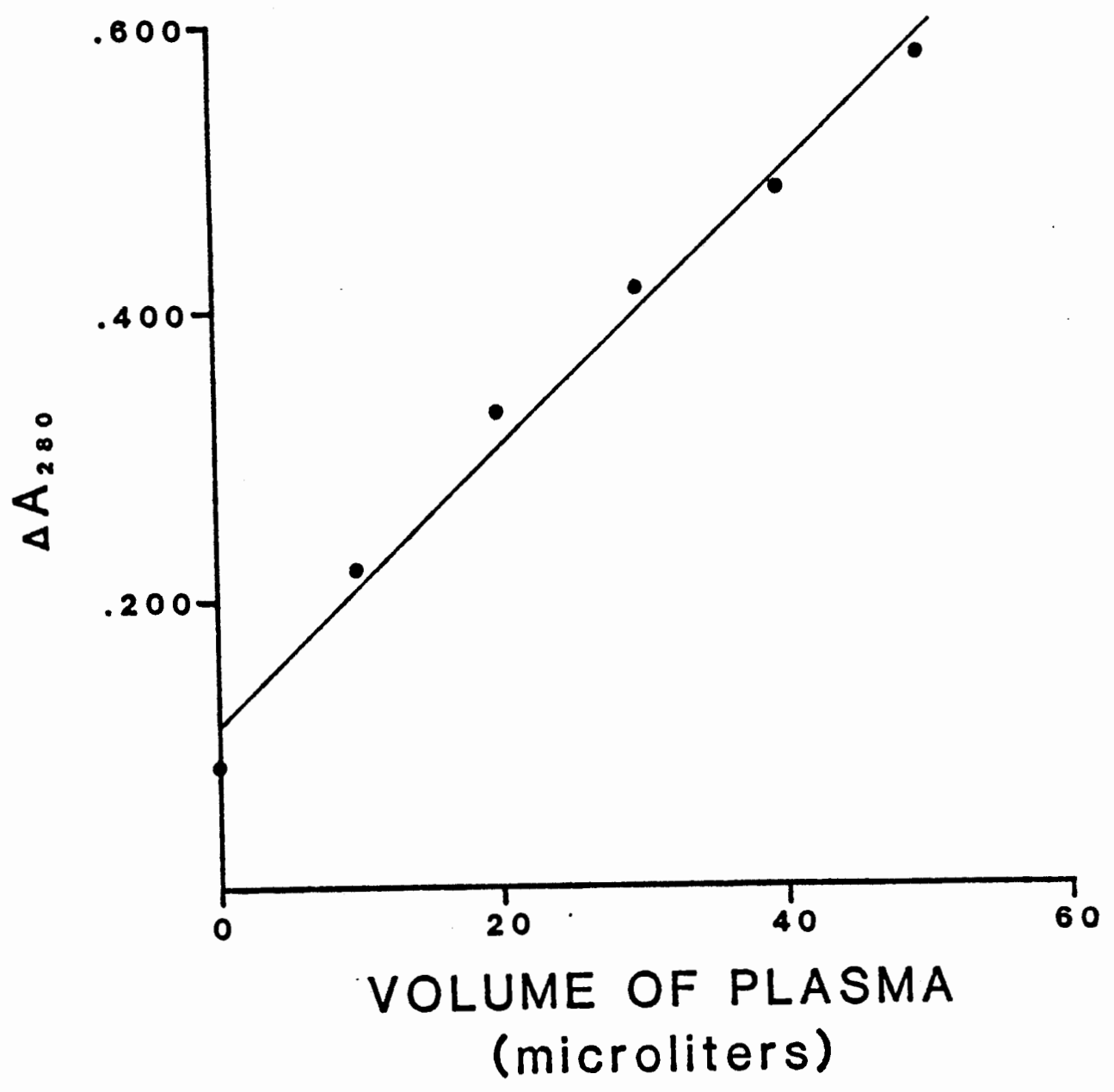


pH range of the assay. Therefore, of all the known cathepsins, only the aspartic and cysteine endopeptidases (if present) should be detected by this procedure. The comparison of the results obtained with this assay to those published in the literature is complicated by the fact that the $\mathrm{pH}$ optima of the various cathepsins are not absolute. The relationship between activity and pH for a given cathepsin may depend on the source of the enzyme, the nature of the substrate (Barrett, 1978), the buffer used in the assay (Otto, 1971), and even the incubation time (Woessner, 1971). Thus, published results for mammalian cathepsins, especially using substrates other than hemoglobin or buffers other than citrate-phosphate, would not be expected to agree precisely with the results of this investigation.

When toad plasma was assayed for cathepsin activity in the absence of cysteine, the sulfhydryl-dependent endopeptidases were presumably excluded from the reaction. Therefore, Figure 2 shows only sulfhydryl-independent activity corrected for the "background" activity seen in Figure 1. The pH relationship of this net activity is consistent with data in the literature for cathepsins $D$ and E. Published values for the $\mathrm{pH}$ optimum of hemoglobin digestion by cathepsin $D$ range from 2.8 to 4.0 , with many reports of peak activity at or near pH 3.0 (Press et al., 1960; Iodice et al., 1966; Barrett, 1971). The decrease in 
activity with increasing $\mathrm{pH}$ was much more rapid in the present study than is usually reported for cathepsin $D$, however. Cathepsin D typically retains some activity above pH 5.0, contrary to the results presented here. Cathepsin E hydrolyzes serum albumins more readily than hemoglobin (Lebez et al., 1971), but has been reported to digest hemoglobin optimally at pH 2.5-3.5 (Barrett, 1969). The "background" activity seen at low pH may be the result of acid denaturation or degradation of the substrate. Hemoglobin begins to dissociate into subunits at $\mathrm{pH} 4.5$ (Barrett, 1969) and may be further degraded at lower $\mathrm{pH}$ under the conditions of this assay. This degradation could be a direct result of the acidic conditions or the result of some other reaction facilitated by the dissociation of the hemoglobin molecule (Bohley et al., 1971).

Activity measured in the presence of cysteine should reflect total plasma cathepsin activity, including both sulfhydryl-dependent and sulfhydryl-independent enzymes. Accordingly, the more acidic peak observed in the sulfhydryl assay (Figs. 3 and 4 ) is very similar to the results obtained without cysteine and probably represents cathepsins $D$ and $E$ also. Cathepsin S, a cysteine endopeptidase with maximum activity against hemoglobin at pH 3.0 (Turnsek et al., 1975), may also be involved, although it is found in very small quantities in typical lysosomes (Takio et al., 1983). The addition of cysteine to the substrate solution 
caused a slight increase in "background" proteolytic activity at low $\mathrm{pH}$, either by facilitating the acid denaturation of hemoglobin or by introducing or promoting some other biological reaction (see below).

While no activity was observed above $\mathrm{pH} 4.5$ in the sulfhydyrl-free assay, a very large peak appeared with the addition of cysteine (Fig. 3). However, most of this "plasma cathepsin activity" is spurious, since it also appeared when shock plasma was omitted from the assay. The actual plasma-dependent cathepsin activity had an optimum pH in the range $5.0-5.4$ (Fig. 4). Cathepsin Bl is one of the major thiol endopeptidases in lysosomes (Taylor and Tappel, 1974) and was probably the source of much of this activity. The $\mathrm{pH}$ optimum for hemoglobin hydrolysis by cathepsin Bl varies, depending on the source of the enzyme or conditions of the assay, from as low as $\mathrm{pH} 4.0-4.5$ (Otto, 1971) to as high as pH 6.Ø (Barrett, 1973). Cathepsin L (pH optimum 5.ø-5.5) may also be involved. Cathepsin $L$ has much greater activity than cathepsin Bl against most proteins (Kirschke et al., 1977), but has relatively low activity against hemoglobin (Barrett and Kirschke, 1981). Cathepsin H varies between species in its proteolytic activity and thus may or may not have contributed in this instance (Barrett and Kirschke, 1981). Of the the remaining cysteine endopeptidases, cathepsin $S$ is not active at this $\mathrm{pH}$ (Turnsek et al., 1975), cathepsin $\mathbf{N}$ appears to hydrolyze 
only collagen (Evans and Etherington, 1978), cathepsin $M$ is more or less specific for aldolases (Pontremoli et al., 1982), and cathepsins $P$ and $T$ are present only in small quantities in most lysosomes (Takio et al., 1983). Cathepsins $J$ and $R$ were isolated only recently (Liao and Lenney, 1984) and have not been fully characterized.

The "background" activity observed above pH 4.5 was clearly related to the presence of cysteine. Some type of biological contamination was suspected, since the conditions of the assay (warm temperature, relatively mild $\mathrm{pH}$, and long incubation time) seem ideal for the growth of bacteria or other microorganisms using the hemoglobin as medium. Because no such growth was evident when cysteine was not included in the substrate solution, it is likely that the cysteine itself was contaminated or that it was an essential nutrient of the microorganisms.

Using this information, two assays may be described for cathepsin activity in toad plasma. Tha first, for cathepsin D-type activity, would be performed at $\mathrm{pH} 3.0$ in the absence of cysteine; the second, for cathepsin Bl-type activity, would be performed with cysteine at a pH between 5.0 and 5.4 .

Although there is some evidence that intralysosomal $\mathrm{pH}$ may drop as low as 3.0 (Rous, 1925; Goettlich-Riemann et al., 1971), it is unlikely that this degree of acidity is widespread in the ischemic pancreas, even in severe shock. 
Thus, the activity of cathepsin $D$ must be extremely localized at best. Glenn and Lefer (1971) proposed that enzymes active at $\mathrm{pH} 5.5$ (the intracellular $\mathrm{pH}$ of splanchnic tissues) would be far more important in the production of MDF by the ischemic pancreas. On this basis alone, it would seem that the assay for cathepsin Bl-type activity would be a better measure of the shock state.

However, the assay for cathepsin D-type activity is simpler and suffers from fewer complications. In particular, the "background" proteolytic activity inherent in the $D$ assay is far less than that associated with the Bl assay. Working at low $\mathrm{pH}$ and omitting cysteine reduces the likelihood of bacterial contamination.

Therefore, I chose to use cathepsin D-type activity as an indicator of overall plasma cathepsin activity and thus the degree of circulatory shock. This was apparently the assumption made by Curtis and Lefer (1980) in their study of hemorrhagic shock in cats. If pancreatic lysosomes are disrupted as a consequence of hypoxia, then all the enzymes therein will be released and any one may be used as an indicator of lysosomal damage. This assumption is valid so long as the lysosomes are homogeneous, containing the same cathepsins in like quantities. There is recent evidence, however, that this is not true. Crie et al. (1983) found that cardiac cathepsin $D$ activity did not necessarily correlate with cathepsin Bl activity or with the rate of 
protein degradation in rat hearts subjected to various treatments. Even so, cathepsin D activity has been shown to be a reliable indicator of MDF production (Litvin et al., 1973) and will be so used in this investigation. The relationship between plasma cathepsin D-type activity and time of incubation at $37^{\circ} \mathrm{C}$ was linear for reaction times up to 18 hours (Fig. 5). The net absorbance at $280 \mathrm{~nm}$ for 18 hours of incubation was 0.800 , or approximately $\emptyset .7$ when corrected for the spurious activity at zero time. This latter value probably represents an upper limit to net absorbance over the linear range of this assay; i.e., any value for net absorbance at $280 \mathrm{~nm}$ that exceeds 0.7 must be regarded as suspect, since absorbance is no longer proportional to reaction time. Previous studies have found a more limited range of linearity (up to 0.3 net absorbance at $280 \mathrm{~nm})$, but these assays were performed on purified enzyme preparations over much shorter incubation times (Barrett, 1970; Takahashi and Tang, 1981). This departure from linearity may be caused by the build-up of inhibitory products, by the self-digestion of the enzyme, or by depletion of the substrate.

In order to use a 24-hour incubation time, it was necessary to double the volume of substrate solution used, effectively halving the concentration of enzyme in the assay. Net absorbance at $280 \mathrm{~nm}$ after 24 hours was then positively correlated to the amount of toad plasma assayed 
for volumes from $\emptyset-0.05 \mathrm{ml}$ (Fig. 6). The $y$-intercept of the regression line for this data ( $\emptyset .113)$ is "background" activity not associated with the plasma. The relationship between activity and volume of plasma is quite linear up to a corrected net absorbance of 0.5 . Since increasing the reaction time is equivalent to increasing the amount of enzyme (or plasma), this relationship should also be linear up to 0.7 net absorbance (see above).

The final form of the cathepsin assay to be used for toad plasma was determined by these results. It is based on the sulfhydryl-free assay described in the Materials and Methods section of this chapter. The hemoglobin substrate solution will have a final $\mathrm{pH}$ of 3.0 and will not contain cysteine. A volume of toad plasma between $0.01 \mathrm{ml}$ and $0.04 \mathrm{ml}$ will be used in each assay, the volume to be adjusted such that the net absorbance at $280 \mathrm{~nm}$ does not exceed 0.7 . The assay mixture will be incubated at $37^{\circ} \mathrm{C}$ for 24 hours and analyzed as before. The net absorbance at $280 \mathrm{~nm}$ so obtained will be corrected for "background" activity by subtracting 0.113 . In this way, assays using different volumes of toad plasma may be compared directly.

One limitation of this assay procedure is that it is relatively non-specific. Although the activity it measures is characteristic of cathepsin $D$, other proteolytic enzymes may also be involved. Hemoglobin is a suitable substrate for many proteinases, particularly when denatured by acidic 
conditions over 24 hours (Bohley et al., 1971). But this assay has the virtues of simplicity and practicality, and did give repeatable results in preliminary work with toad plasma. 
CHAPTER III

\section{DEHYDRATION AND CIRCULATORY SHOCR \\ IN BUEO MARINUS}

\section{INTRODUCTION}

The physiological consequences of dehydration in the toad Bufe marinus have been described in detail by shoemaker (1964). This study provides evidence that cardiovascular degeneration is the proximate cause of death in severely dehydrated toads. When water loss exceeds $20-25 \%$ in this species, both circulating plasma volume and arterial pressure fall off sharply, indicative of circulatory collapse.

The importance of prolonged hypovolemia in the cardiovascular debilitation leading to this collapse is unknown. In particular, it is not known whether Bufe marinus -- or indeed any anuran -- suffers from circulatory shock as a result of dehydration. If hypovolemia is directly responsible for the circulatory failure in dehydrational death in anurans, it should be possible to demonstrate the existence of a shock state in these animals, even if only in the terminal collapse of the circulation.

As discussed in the General Introduction, progressive circulatory shock is characterized by a number of positive- 
feedback systems. Among these, the production of a myocardial depressant factor (MDF) by the ischemic pancreas has been the subject of many recent investigations (see Lefer, 1978). MDF has been found in the plasma of mammals suffering from many types of shock, including hemorrhagic, septic, cardiogenic, and splanchnic ischemic shock (Lefer, 1978). At present, plasma MDF activity must be determined with a complicated bioassay using isolated cat papillary muscles (Leter et al., 1967). However, certain cathepsins appear to be essential in the biosynthesis of MDF (Glenn and Lefer, 1971; Ferguson et all., 1972; Lefer and Barenholz, 1972; Letfler et al., 1973; Litvin et al., 1973). In particular, cathepsin $D$ has been shown to be a reliable indicator of MDF production (Litvin et al., 1973; Curtis and Lefer, 1980).

In mammals, circulatory shock may also be induced by splanchnic artery occlusion (SAO), resulting in ischemia and hypoxia in the visceral organs, including the pancreas (Lefer and Barenholz, 1972). SAO shock has been shown to involve lysosomal disruption and increased plasma proteinase and MDF activity (Lefer and Barenholz, 1972; Leffler et al., 1973; Curtis and Lefer, 1981). Occlusion is accomplished by ligating the celiac, superior mesenteric, and inferior mesenteric arteries (Curtis and Lefer, 1981). In anurans, the celiac and superior (anterior) mesenteric arteries are branches of the celiaco-mesenteric artery which arises from 
the ventral aspect of the dorsal aorta immediately posterior to the junction of the two systemic arches and supplies blood to the abdominal viscera (Bohensky, 1982). The inferior (posterior) mesenteric artery arises independently from the dorsal aorta and supplies the rectum. SAO shock has never been attempted in anurans, but ligation of the celiaco-mesenteric artery should occlude splanchnic blood flow sufficiently to determine whether or not SAO shock can be induced in these animals.

I propose to use plasma cathepsin D activity as an indicator of circulatory shock. To my knowledge, this has never before been done in anurans. Two experimental groups will be examined: one group of toads will be dehydrated to produce a hypovolemic condition; the second group will be subjected to ligation to produce splanchnic ischemia. Plasma cathepsin activity in the former will be used to evaluate the degree of shock caused by dehydration. The extent of hypovolemia will be evaluated by changes in plasma sodium, potassium, and protein concentrations and hematocrit with dehydration. Ligation should also produce shock enzymes if the splanchnic hypothesis for cathepsin release applies to anurans. 


\section{MATERIALS AND METHODS}

\section{Animals}

Bufe marinus were purchased from commercial suppliers. The toads were maintained on soil at room temperature with access to water in shallow pans but were not fed. No attempt was made to control photoperiod.

\section{Cannulation and Bleod Sampling}

The ventral abdominal vein of each toad used in this experiment was cannulated occlusively to permit periodic blood sampling. Toads were anesthetized by partial immersion in a solution of tricaine methanesulfonate (MS-222). A small incision was made in the abdominal skin and muscle to expose the ventral abdominal vein. A short section $(1-2 \mathrm{~cm})$ of this vessel was isolated and the heat-flared end of a polyethylene cannula (PE-9ø) filled with heparinized saline $(0.98 \mathrm{NaCl})$ was inserted caudally through a nick in the vessel wall. The cannula was secured in place with silk thread tied around the vein and the muscle and skin were sutured closed. The patency of the cannula was verified and $\emptyset .5 \mathrm{ml}$ heparinized saline infused into the toad. The free end of the cannula was then sealed with a metal plug. Blood loss during this procedure was minimal.

Sampling was usually accomplished simply by removing the metal plug and allowing the toad's blood pressure to 
force the saline out of the cannula. It was sometimes necessary to flush clotted blood from the cannula using a syringe of heparinized saline, then allow the saline to drain as before. The first few drops of blood were discarded, since they were diluted with saline. Blood was collected in $0.2 \mathrm{ml}$ heparinized glass tubes which were then sealed at one end. A total of approximately one milliliter of blood was taken from each toad per sampling period. The cannula was then flushed with just enough heparinized saline to force all blood back into the animal and the metal plug was replaced. Hematocrit was determined following centrifugation at $1000 \times \mathrm{x}$ for 15 minutes and is reported as the average value obtained for each sampling period. The plasma was separated and frozen for later analysis.

\section{Debydration}

Toads selected for dehydration were allowed to recover from cannulation for 24 hours in individual chambers with access to tap water. At this point, an initial blood sample was taken as described above. The hydrated mass of each toad was determined (to the nearest $0.1 \mathrm{~g}$ ) after it was blotted dry and its bladder drained by inserting a glass tube into the cloaca and applying pressure to the lower abdomen. The toads were dehydrated in individual plastic chambers covered by wire screens, and were kept at room temperature and weighed periodically. Blood samples were 
taken at or near losses of $10 \%$ and 208 initial (hydrated) body mass, if possible. Frequently, blood flow through the cannula became very slow or stopped as dehydration proceeded and no blood could be obtained. A final sample was taken at the critical activity point (CAP; Hillman, 1978b). At CAP, the toad was doubly pithed, weighed, and blood withdrawn directly from the exposed ventricle by heparinized syringe. Several toads died before the CAP sample could be taken. A total of nine animals were used to obtain at least five blood samples at 108 loss, 208 loss, and CAP.

\section{Ligation}

In toads to be subjected to ligation, the initial blood sample was taken immediately after cannulation. While still under anesthesia, the body cavity was opened by a lateral incision. Two ligatures were tied around the celiaco-mesenteric artery to block splanchnic blood flow and the muscle and skin were sutured closed. The toads were weighed with bladders drained as before and placed in individual chambers with access to tap water. Blood samples were collected from these animals via the ventral cannula one day and four days after surgery. One week after ligation, each toad was doubly pithed and a large blood sample was withdrawn from the exposed ventricle by heparinized syringe. The lateral incision and internal 
organs were examined post mortem and placement of the ligatures was verified.

\section{Controls}

Control toads were cannulated as described above but were otherwise untreated. Blood samples were taken immediately after cannulation and following one, four, and five days in individual chambers with access to tap water.

\section{Plasma Analyses}

Sodium and potassium concentrations were determined with an Instrumentation Laboratories Model 143 flame photometer. Plasma was diluted by adding $0.02 \mathrm{ml}$ of the sample to $4.0 \mathrm{ml}$ lithium diluent. The instrument was calibrated with standard solutions of sodium and potassium encompassing the range of concentrations in the samples. The calibration and reliablity of the instrument were verified by frequent use of a standard solution during the course of analysis.

Total protein was determined by the Biuret method, using human serum protein $(8.0 \mathrm{~g} / 100 \mathrm{ml}$, sigma) as the standard. Each plasma sample was assayed in duplicate and the mean value reported for protein concentration.

Plasma cathepsin activity was assayed as described in Chapter II, using a volume of plasma between $\emptyset .01 \mathrm{ml}$ and $\emptyset .04 \mathrm{ml}$ in duplicate control and experimental assays. If the net absorbance at $280 \mathrm{~nm}$ was in excess of 0.7 , the 
results were discarded and the analysis repeated using a smaller volume of plasma. One unit of cathepsin activity (cathepsin unit, C.U.) is here defined arbitrarily as that amount of enzyme which produces a net absorbance at $28 \emptyset \mathrm{nm}$ of 0.01 over 24 hours. Specific activity is expressed as units of cathepsin activity per milligram total protein in plasma (C.U./mg). The precision of this assay was determined to be \pm 48 of net absorbance at $280 \mathrm{~nm}$ based on repeated assays of the same plasma sample.

\section{Statistics}

Data for plasma sodium, potassium, and protein concentrations and hematocrit were subjected to analysis of variance, using the student-Newman-Keuls test to compare individual means within and between treatment groups. Relative plasma cathepsin activities were compared using the nonparametric Kruskal-Wallis test (Zar, 1984). A P<ø.Ø5 was considered significant.

\section{Calculations}

Predicted plasma concentrations for dehydrating toads were calculated by the method of shoemaker (1964). This method assumes an initial whole animal water content of 79.48 , that plasma is 1008 water, and that the plasma volume loses an amount of water proportional to the loss from the whole animal. 


\section{RESULTS}

Mean water loss at CAP for dehydrated Bufe marinus was 31.68 initial body mass $(\mathrm{SE}= \pm 1.18, \mathrm{~N}=6)$. The mean time between surgery and the initiation of dehydration ( $\emptyset_{8}$ water loss) and the mean dehydration times required to reach $10 \%$ loss, 208 loss, and CAP are given in Table IV. This allows direct comparison of the results of dehydration and those from the control and ligation groups based on elapsed time after cannulation.

Plasma sodium concentration increases with dehydration (Table V, Figure 7). Mean plasma sodium concentration at each increment of dehydration is significantly greater than the previous value $(P<\theta .05)$. There is close agreement between predicted and actual sodium concentrations (Table V). There were no significant differences in the control and ligation groups.

Plasma potassium concentration was significantly elevated only in toads dehydrated to CAP ( $P<0.05$; Table VI), although there is also the suggestion of a slight post-operative increase.

Hematocrit increased with dehydration, but not as rapidly as predicted up to 208 water loss (Table VII). Hematocrit at CAP was significantly greater than at lower water deficits $(P<\emptyset . \emptyset 5)$ and slightly greater than predicted. There was a significant fall in hematocrit in ligated toads 
$z 10$ in n 6

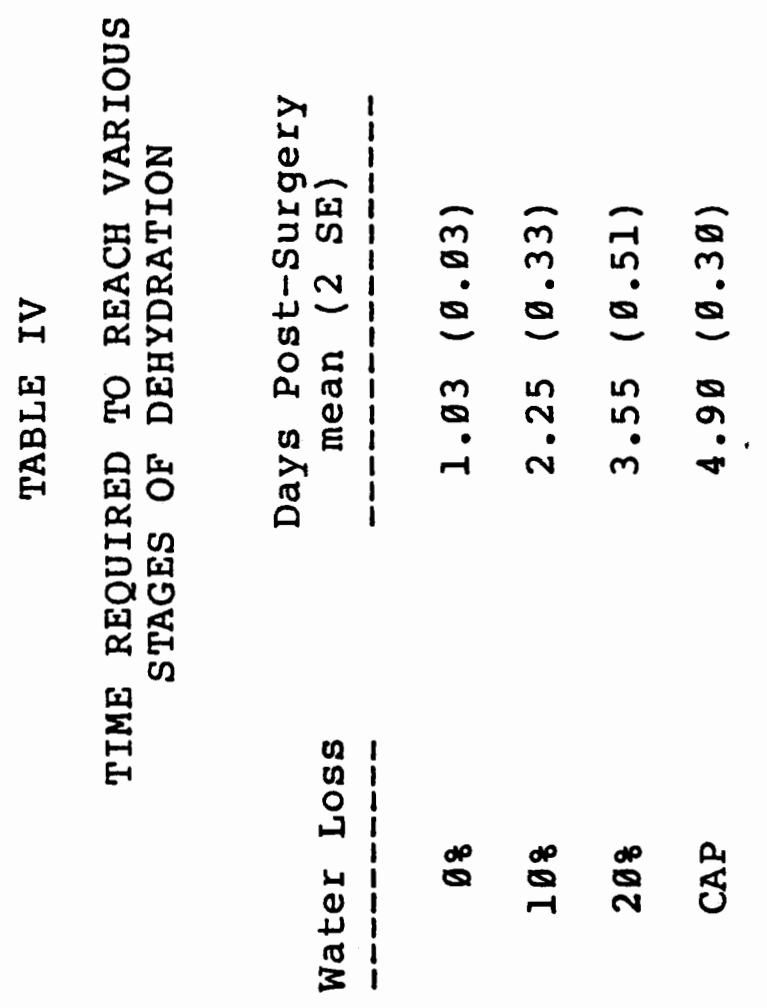




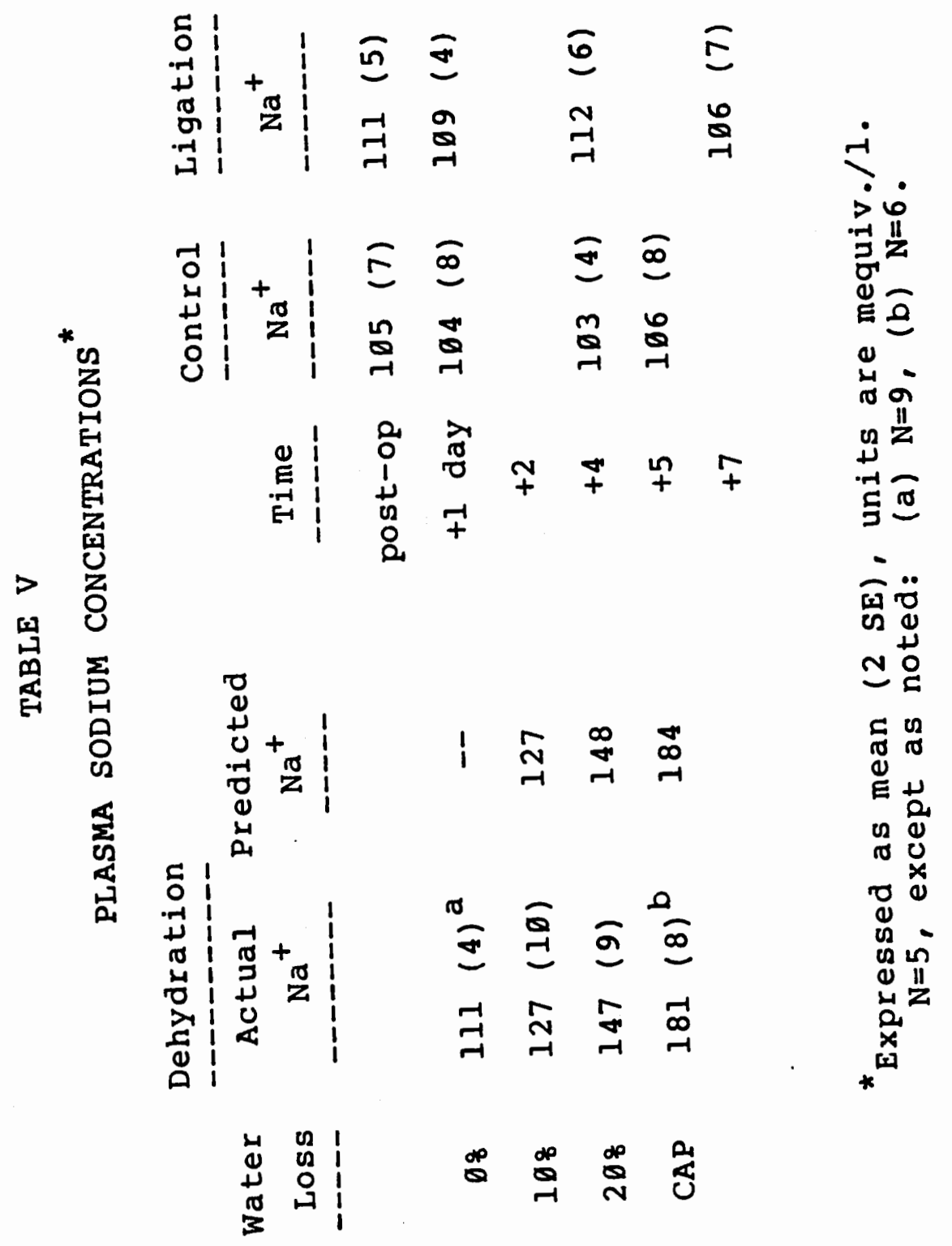


Eigure 7. Mean plasma sodium concentrations for all three treatment groups as related to elapsed time following cannulation. The lines represent \pm two standard errors of the mean. Dehydration times are also mean values (see Table IV). 


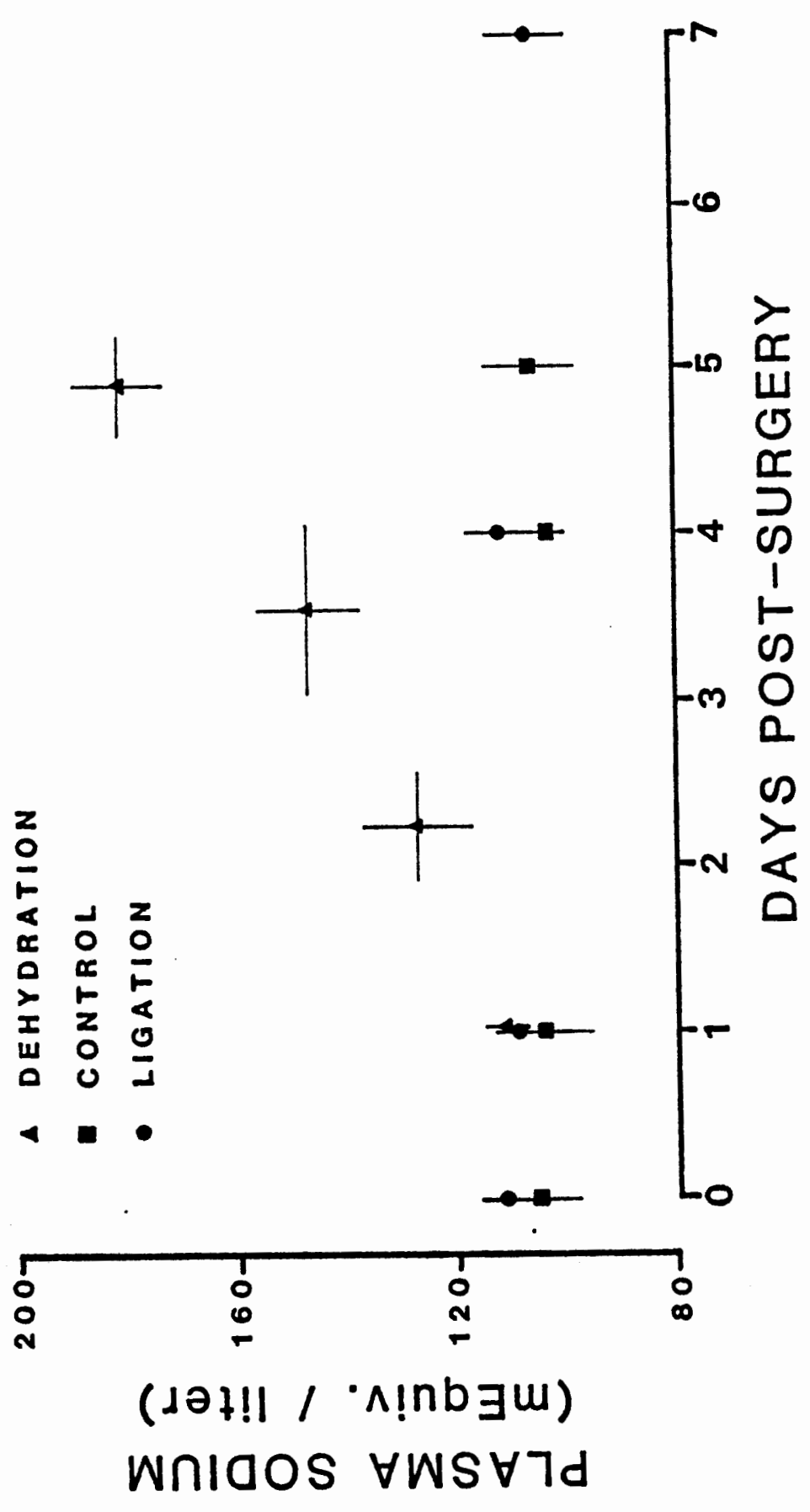




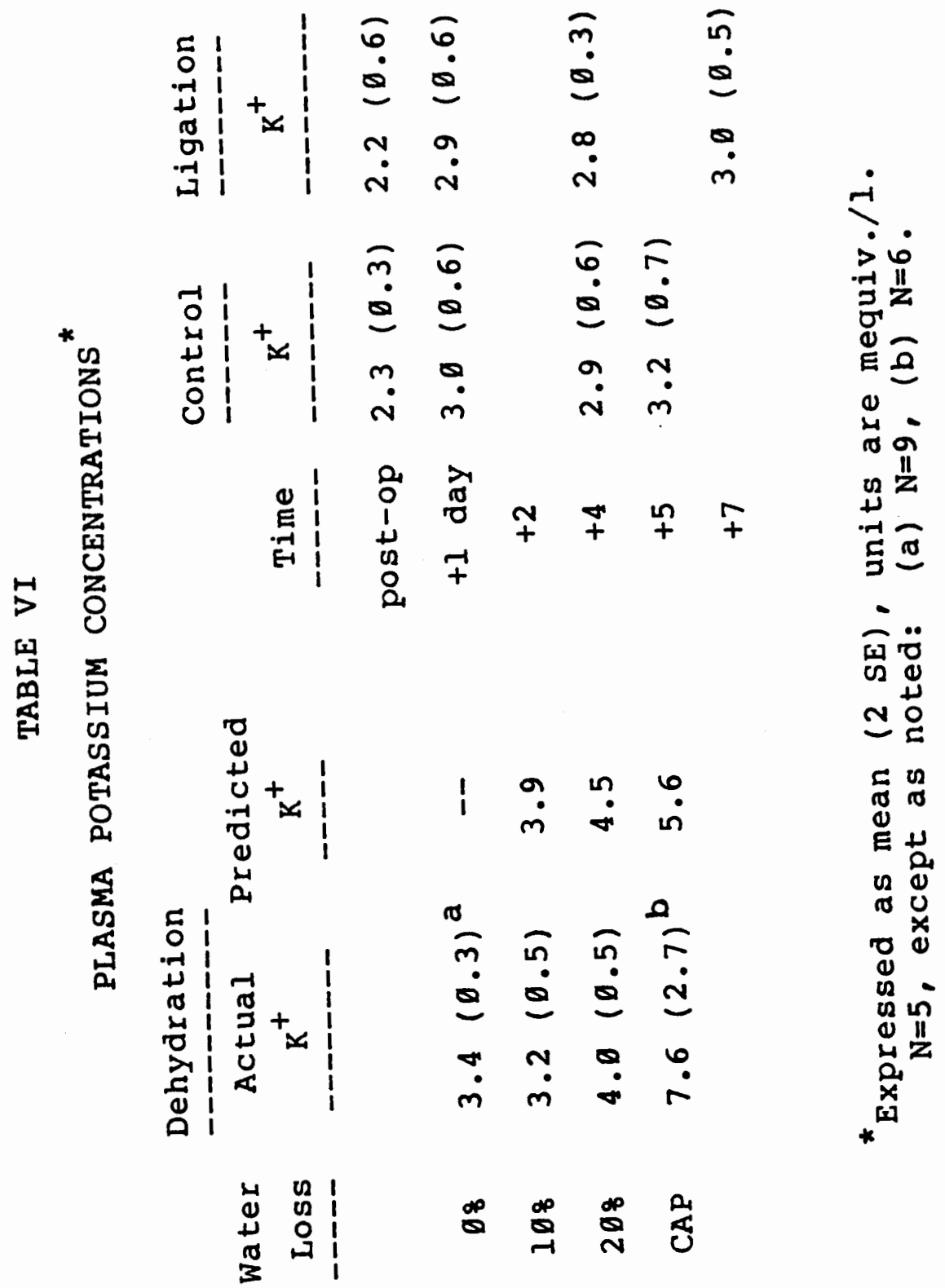




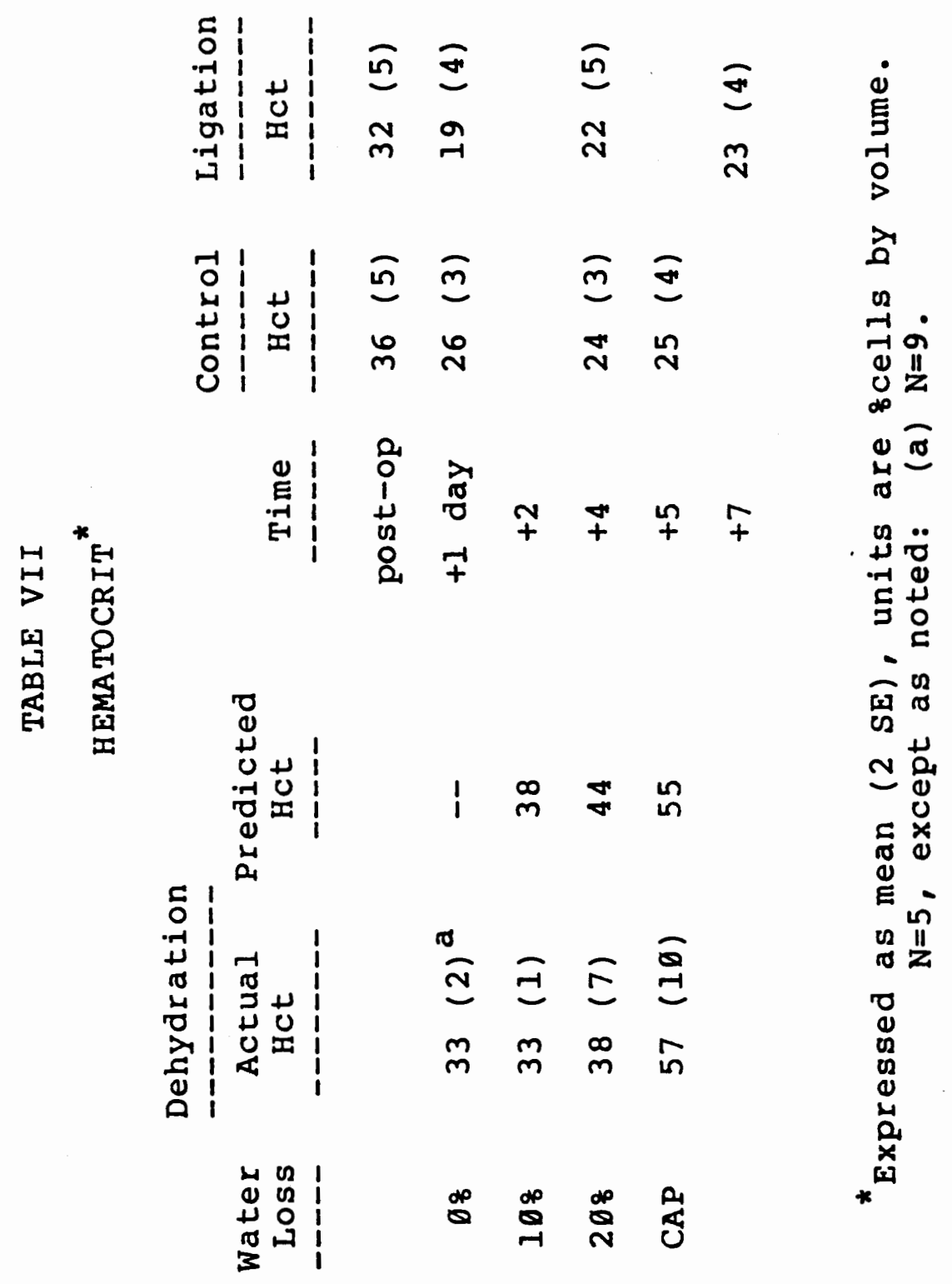


one day after surgery and in control toads four days after surgery $(P<0.05)$. Ligated toads also had a lower mean hematocrit than dehydrated toads on the first day after surgery $(P<\emptyset . \emptyset 5)$, but there was no statistical difference between ligated and control toads on the first day.

Plasma protein concentration rose with dehydration, as predicted, to $20 \%$ water loss (Table VIII). Mean protein concentration at $20 \%$ loss was significantly greater than for hydrated toads $(P<\emptyset . \emptyset 5)$. The mean plasma protein concentration at CAP was greater than the concentration at 208 water loss $(P<\emptyset .05)$, but is also greater than predicted. There were no significant differences in the control and ligation groups.

Initial post-operative or hydrated plasma cathepsin activities were extremely variable (range $=4.7-83.8$ C.U./mg). Mean activites for the first sample from each treatment group are presented in Table IX. Analysis of variance indicated a significant difference between these means $(P<0.05)$, although the Student-Newman-Keuls test did not. The only other initial parameter found to differ significantly between groups was body mass, which showed a similar statistical difference (Table IX). Because of the variability in plasma cathepsin activity, it is expressed below only as relative activity.

There is no significant difference between the mean plasma cathepsin activities within or between any of the 


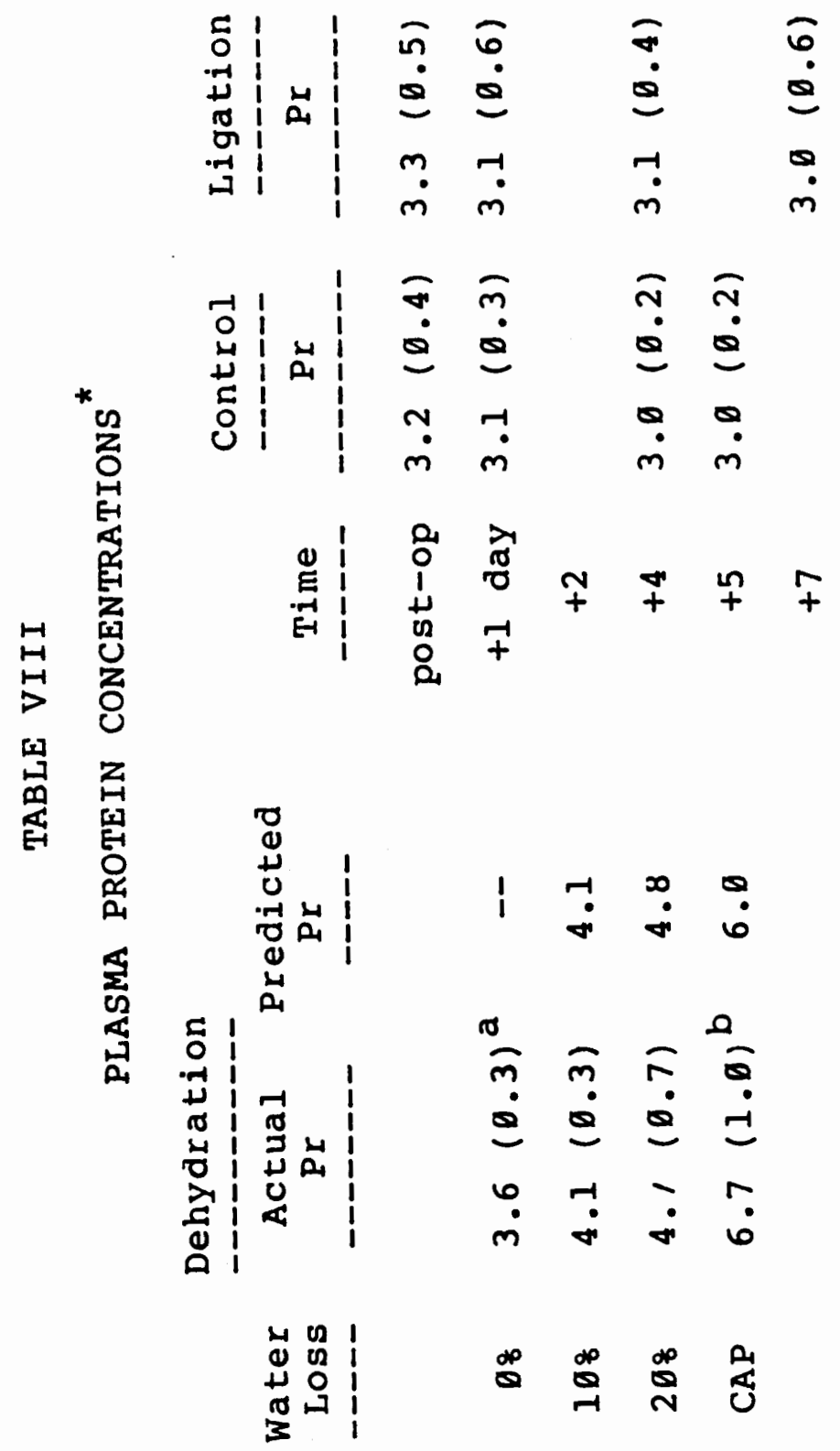

हี

مُ

( )

Z

थ

$+10$

E.

-

ज्ञ

บ

مأم

岂

02

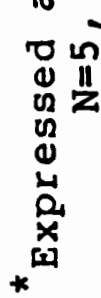


$z !$ a n n

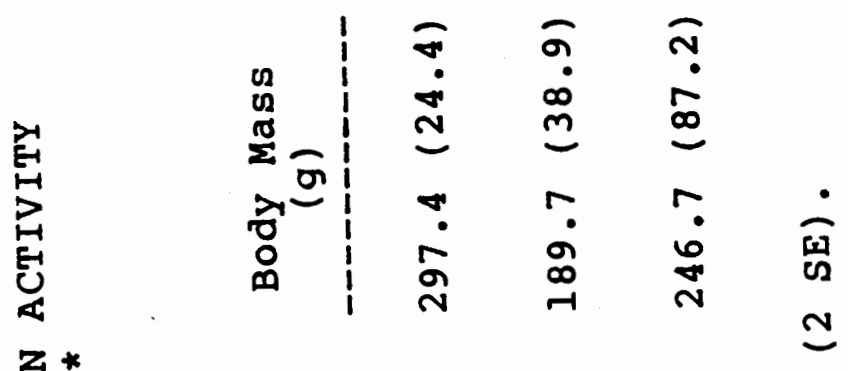

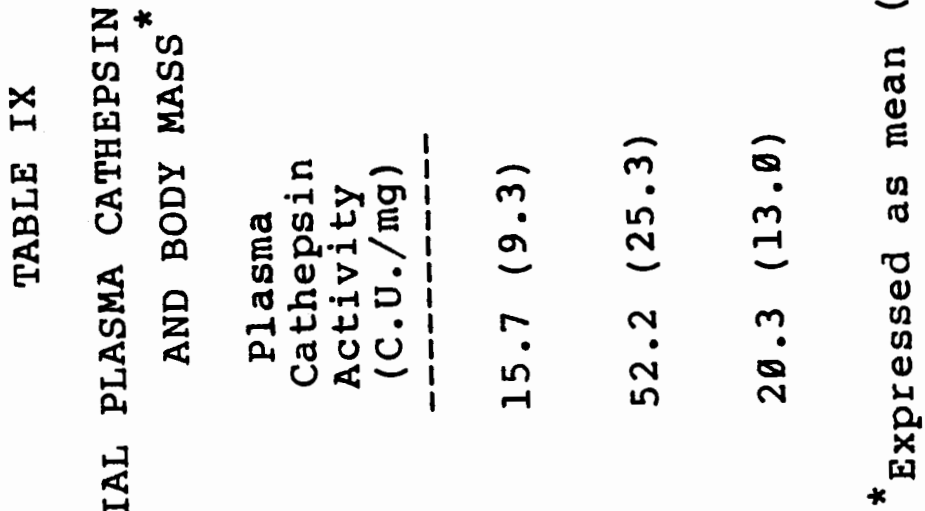

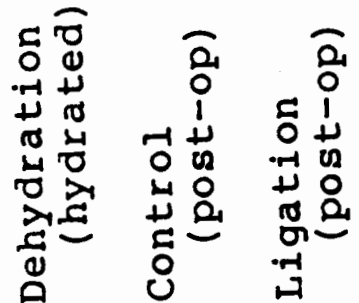


three groups when activities are expressed relative to one day after surgery (the only sampling time common to all three groups; Table $\mathrm{X}$ ). The changes in cathepsin activity over time in the control toads was quite variable, ranging from a slight decrease to a two-fold increase on the fourth day (Figure 8). All values for plasma cathepsin activity in dehydrated toads fell within the range of values for control animals. Two of the ligation toads showed the highest relative activity measured (see below), although the other three were within or below the control range.

If plasma cathepsin activity is expressed not as specific activity (C.U./mg plasma protein) but as absolute activity (C.U./ml plasma), the effects of dehydration can be better appreciated (Table XI). Absolute plasma cathepsin activity increases about as predicted to 208 water loss but rises dramatically at $\operatorname{CAP}(P<\emptyset .05)$. Absolute plasma activity at CAP is twice as high as would be expected from simple concentration effects but is not significantly different from the 4-day control value.

The results of ligation on plasma cathepsin activity should really be related to activity immediately after cannulation and before ligation, as in Table XII. Once again there is no significant difterence within or between groups. However, there is a tendency for cathepsin activity to peak on the fourth day and then decline in both groups (see also Figure 8). Relative to post-operative values, two 


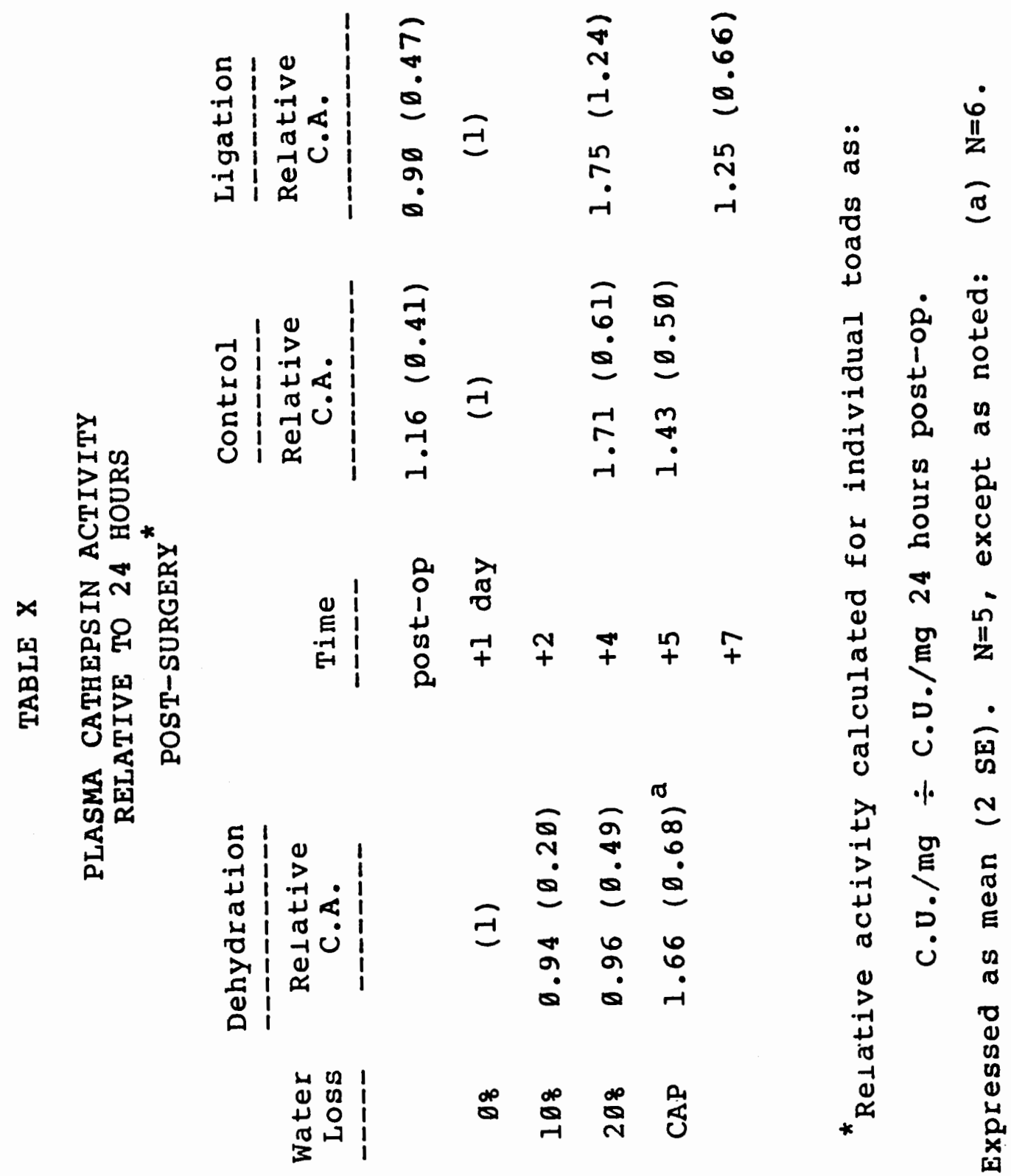


Figure 8. Plasma cathepsin activity relative to 24 hours after cannulation. Lines connect results from the same individual. Single values for dehydrated toads are represented as unconnected triangles. 

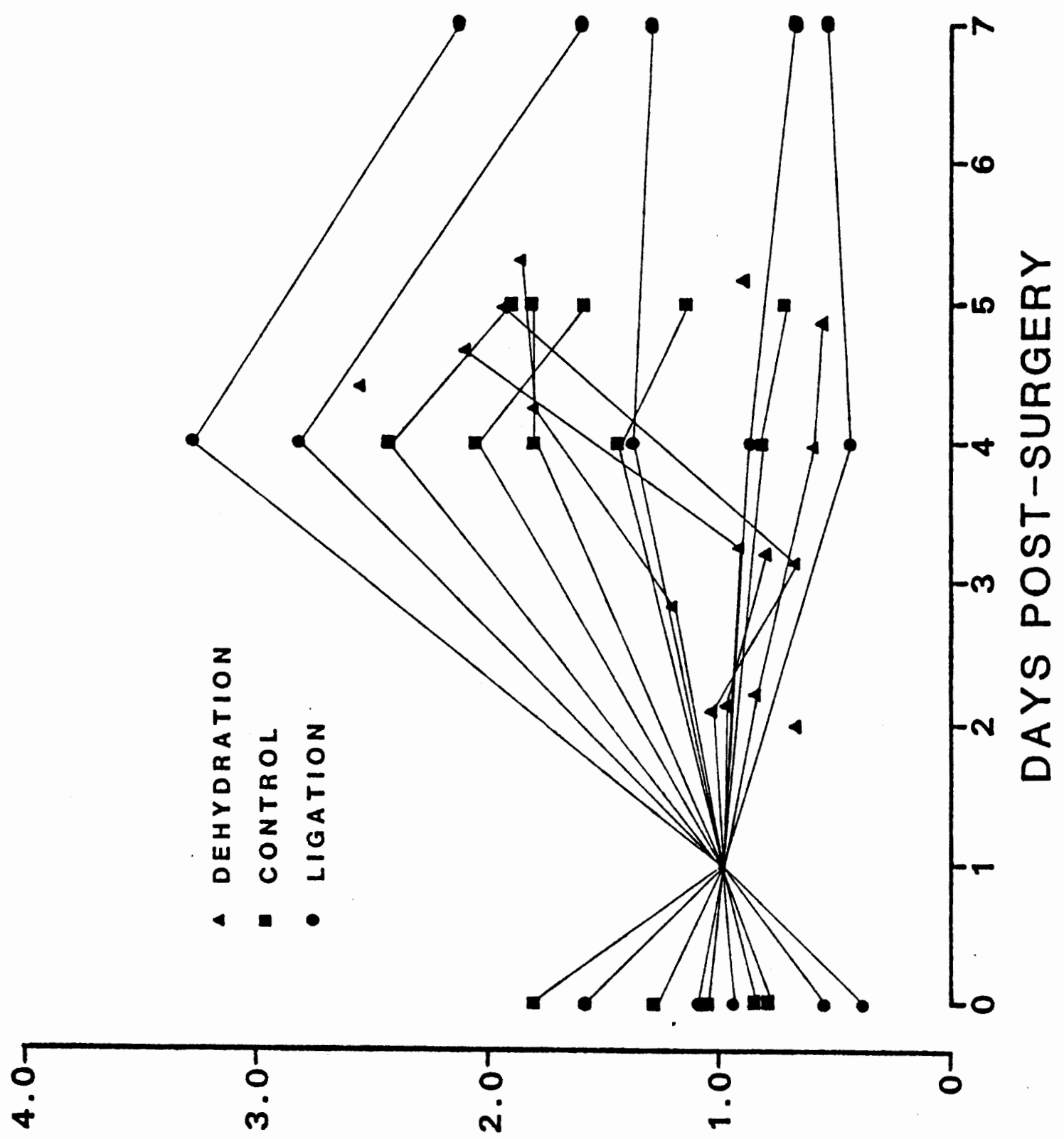

(do-tsod.2AY t

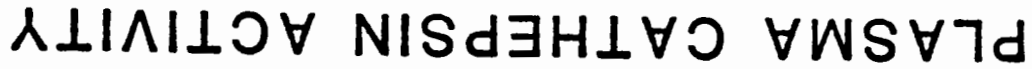




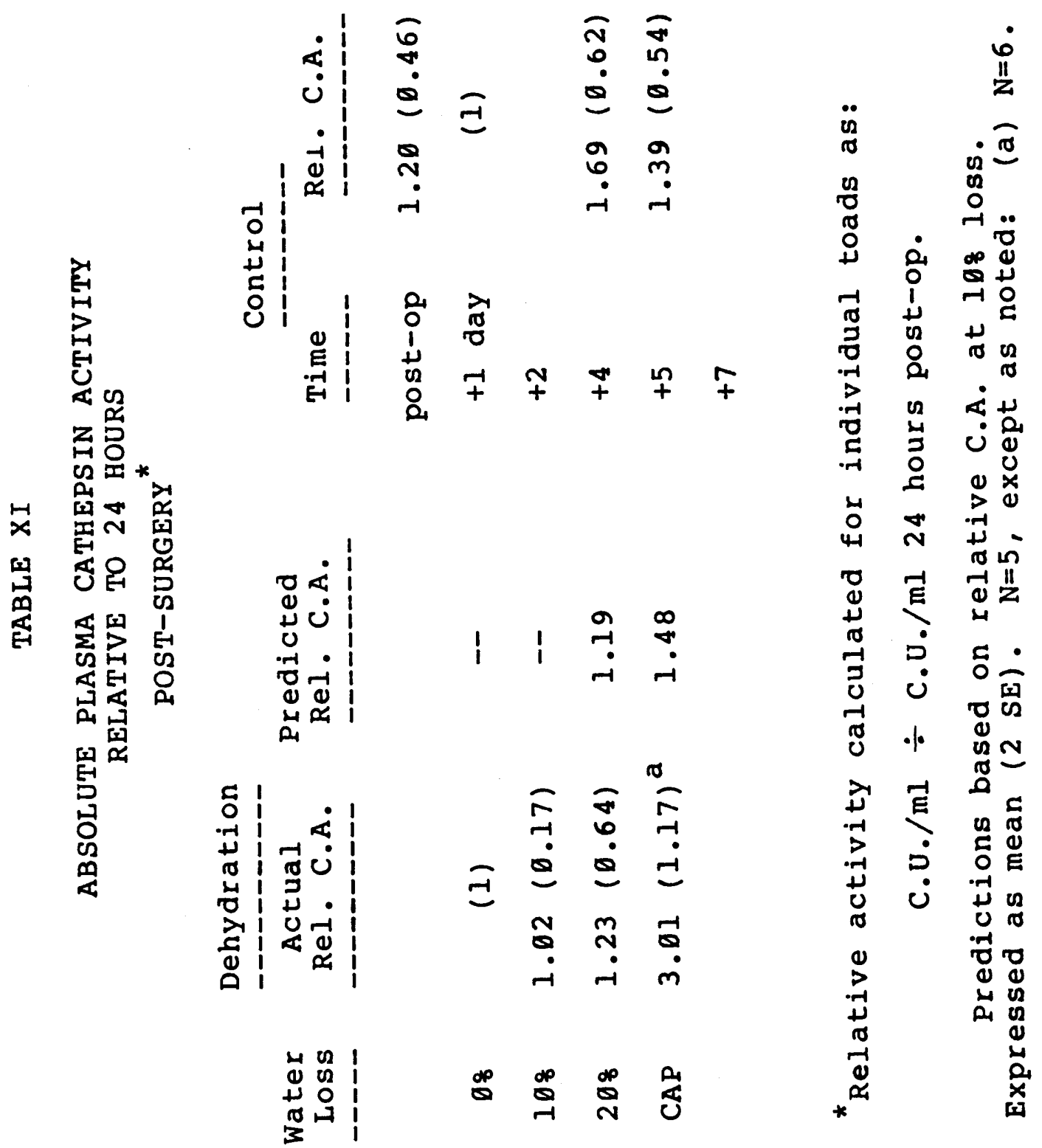




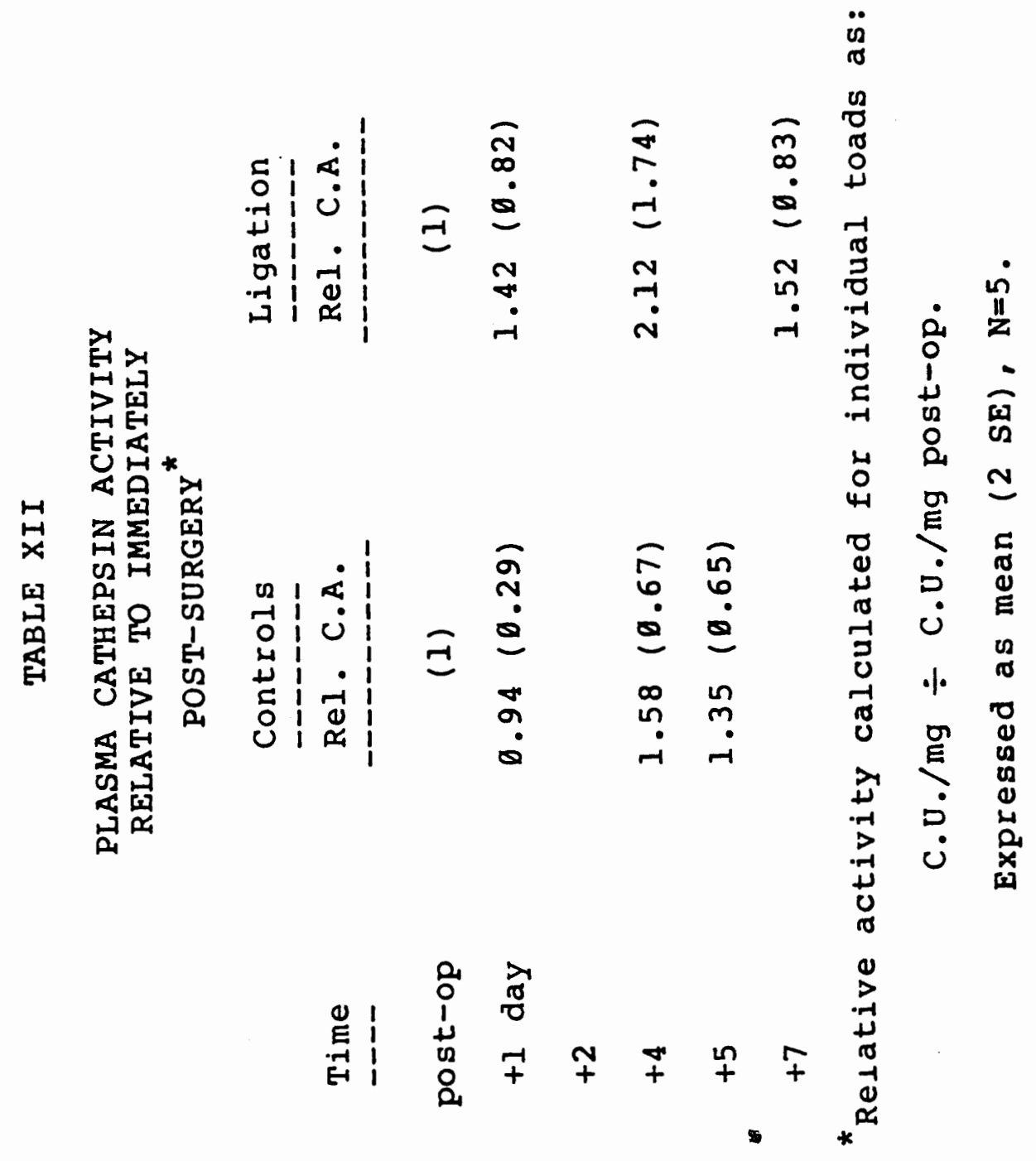


ligation toads showed very high levels of plasma cathepsin activity: one peaked on the first day at 2.66 times initial activity, the other peaked on the fourth day at 5.12 times initial activity.

Post mertem examination of the latter toad revealed a large gelatinous mass associated with the ventral abdominal vein cannula, probably indicating a serious infection. However, no such infection was found in the former. The ligated toad showing the lowest increase in plasma catheps in activity had enlargea, blood engorged vessels in the splanchnic region. Except for these few observations, all ligated toads appeared relatively free of infection and internal abnormalities. The ligatures were in place and occlusion was verified in all animals.

\section{DISCUSSION}

The mean water loss at CAP reported here for Bufe marinus ( 31.68 initial body mass) is considerably lower than expected. Dehydration tolerance in this species has been estimated previously at $38 \%$ water loss using the same criterion of death (Hillman, personal communication). It is likely that stress or sepsis caused by the cannulation procedure or occlusion of the ventral abdominal vein contributed to the reduction in tolerance. If cardiovascular debilitation is the mechanism of 
dehydrational death in anurans, then any factor which exacerbates that debilitation must reduce dehydration tolerance.

Plasma sodium concentration increased with dehydration exactly as predicted by the method of Shoemaker (1964). This calculation assumes that loss of water from any fluid compartment in a toad is proportional to the total evaporative water loss from the animal. The close agreement between actual and predicted sodium concentrations would appear to validate this assumption. However, there is other evidence suggesting that this is not so (see below). In any event, plasma sodium concentration is considered a reliable indicator of dehydration in toads (Shoemaker, 1964). Thus, no significant dehydration or hypovolemia occurred in either control or ligated toads.

Hematocrit was unaffected by 108 water loss and only slightly increased by $20 \%$ loss. Since red blood cell volume does not change with dehydration (Shoemaker, 1964), this suggests that plasma volume is maintained during dehydration at the expense of some other fluid compartment. Shoemaker (1964) reported that toads can maintain plasma volume to 20-258 water deficit, although this was after an initial 358 fall in plasma volume over the first 58 water loss. This initial decline was thought to result from increased capillary hydrostatic pressure and fluid filtration due to renal vasoconstriction. However, mean arterial pressure in 
toads is unaffected by water deficits of 108 or more (Shoemaker, 1964). It seems highly unlikely that an animal which can maintain plasma volume until it has lost one-fourth of its body mass as water would suffer a 358 reduction in plasma volume when dehydrated by only 58 . There is evidence that this initial fall in plasma volume is an artifact of Shoemaker's dilution techniques (Hillman, personal communication). Long equilibration time in a hydrated toad appears to allow the marker to pass through leaky capillaries, leading to an over-estimate of plasma volume. Capillaries become less leaky with the onset of dehydration and the artifact disappears. Thus, plasma volume in toads may be completely maintained until the water deficit reaches $20-25 \%$.

If plasma volume is maintained and yet the sodium concentration increases as expected, then the fluia taken up by the circulatory system must contain sodium. Similarly, since plasma protein concentration rises as predicted with dehydration to 208 water loss, the diluting fluid must also contain protein. Hydrated toads typically contain a large volume of extracellualr fluid in the lymphatic system, coelomic cavity, and interstitial spaces which could act as a reservoir in dehydration (Shoemaker, 1964). Anuran extracellular fluids contain both sodium and protein (Deyrup, 1964) and could be easily transferred to the circulation via the lymphatic system. Extracellular fluid 
volume in toads decreases with dehydration by an amount almost equal to the overall water deficit (Shoemaker, 1964). If plasma volume does not change, then fluid shifts must occur from the other extracellular compartments (lymphatic, coelomic, and interstitial fluids) into the plasma. This is consistent with obseryations on Bana pipiens indicating that up to $80 \%$ of lymphatic fluid is lost with severe dehydration (Smith and Jackson, 1931).

The relatively. large increase in hematocrit and plasma protein-concentration as toads approach CAP is probably due to the falling plasma volume that occurs at water deficits greater than 20-258. (Shoemaker, 1964). Increasing hematocrit and the resulting exponential increase in blood viscosity have been implicated as contributing factors in dehydrational death in anurans (Hillman, 1978a; 1978b; 1980). However, hematocrit would not be expected to have a significant impact on cardiovascular function until after the onset of circulatory collapse, when plasma volume begins to fall. Hyperviscosity may worsen the situation in toads but it cannot be the cause.

Plasma sodium concentrations continued to increase as predicted to CAP and therefore do not reflect the fall in plasma volume at this stage of dehydration. Sodium is removed from the extracellular space in dehydrating xenopus (Hillman, 1978a) and in Bufe marinus muscle and liver tissue have been shown to take up sodium and potassium as a means 
of retaining water (Shoemaker, 1964). Plasma sodium concentration near CAP would thus represent a dynamic relationship between hemoconcentration and tissue uptake and not a static indicator of plasma volume changes in toads as Shoemaker has proposed.

Changes in plasma potassium concentration with dehydration are complicated by the fact that lysis of red blood cells can lead to highly variable potassium levels (Hillman, 1978a). There is no evidence of lysis in the present study, however, except at CAP. The standard error of this mean is 4-5 times greater than any other, suggesting that lysis may have exaggerated the increase in plasma potassium with dehydration. That plasma potassium concentration does not rise as predicted is evidence for the removal of this ion from the extracellular space, as described previously for Bufe marinus (Shoemaker, 1964) and Ambystoma tigrinum (Alvarado, 1972).

Hematocrit was the only measured parameter to change significantly in control or ligated toads. It fell more rapidly in ligated than control animals which would indicate that stress may be partly responsible. Ligation is clearly not the sole cause, however. Toads isolated in individual chambers with access to water have a tendency to sit for long periods of time in the water, which provides the only available "cover." The decrease in hematocrit is probably just a consequence of passive water uptake. Plasma ionic 
and protein concentrations are apparently adjusted with pre-existing stores of these components, but red blood cell production is not fast enough to maintain hematocrit. A similar decrease in hematocrit after surgery has been noted in the bullfrog Rana catesbeiana (Herman and Sandoval, $1983)$.

The extreme variability in initial plasma cathepsin activity was unexpected, since the first blood samples presumably represented the normal resting state of these animals. The differences in mean initial activity between groups can probably be explained by the fact that the toads in each group came from different shipments from the supplier. The treatment groups were examined consecutively, not concurrently, since no significant difference was expected among initial samples. High levels of plasma cathepsin activity could potentially result from any number of stressful conditions, including infection (see below), injury, or fasting. Animals of low body mass appear to be particularly susceptible (see Table IX) •

Overall, relative plasma cathepsin activity increased in 10 of 19 toads studied and remained unchanged or fell in the other nine. Relative activity increased in 3 of 5 control toads, suggesting a stimulus for cathepsin release other than dehydration or ligation. Circulatory problems associated with occlusive cannulation are probably not responsible since this should have affected all animals more 
or less equally. However, the degree of infection following surgery could vary considerably. The cathepsin/MDF pathway has been linked previously to septic shock in mammals (Lefer, 1978). Varying levels of post-operative infection and septic shock is the most straightforward explanation for different plasma cathepsin activities in control toads and in dehydrated and ligated toads as well.

There was no measurable effect of dehydration on relative plasma cathepsin activity over and above controls. Activity increased only near CAP and then only in 4 of 9 toads. This is entirely reasonable since it appears that no hypovolemia occurs in toads until the level of dehydration approaches CAP (see above). Even at CAP, however, plasma cathepsin activity is not significantly elevated above controls. The effects of hemoconcentration on relative activity are largely negated since it is specific cathepsin activity (C.U./mg) and is expressed relative to a plasma protein concentration which is also increasing. Three of the five ligated toads showed increases in relative plasma cathepsin activity but only two were in excess of the control range. It is possible that these two toads suffered from particularly severe infections (one gave this appearance pest mertem) but it is also possible that the effectiveness of splanchnic artery occlusion varied in this group. Flow through the celiaco-mesenteric artery was substantially if not totally blocked by the two ligatures, 
but plastic casts of the arterial system of Bufo marinus indicate the possibility of collateral circulation to the splanchnic region (Hillman, personal communication). The variation in plasma cathepsin activity could thus be due to differential utilization of collateral vessels. In particular, the inferior mesenteric artery to the rectum was not ligated in the present study, although it is ligated to produce SAO shock in mammals (Curtis and Lefer, 1981).

In any event, Bufo marinus proved to be remarkably resistant to SAO shock. This is a highly lethal form of shock in mammals (Lefer and Barenholz, 1972). In one experiment, occlusion of the three splanchnic arteries for only 2.25 hours caused the death of 6 out of 7 cats (Curtis and Leter, 1981). The ligatures are usually released after some time to allow blood flow to flush the products of splanchnic ishemia into the circulation. This was not possible in toads. Nevertheless, these toads were subjected to substantial or complete splanchnic ischemia for 7 days and yet survived with no obvious ill effects. Since SAO shock is intended to mimic the splanchnic ischemia present in hypovolemic shock, the conclusion that toads do not suffer from either form of shock is consistent.

These experiments have shown no evidence of hypovolemic shock with dehydration in Bufe marinus. Hypovolemia does not occur in toads until water loss exceeds 2ø-25\% hydrated body mass. It would be interesting to 
repeat this work on a species such as Xenopus laevis in which plasma volume is not maintained with dehydration (Hillman, 1978a). 
GENERAL DISCUSSION

The results of this study suggest that hypovolemia is relatively unimportant in dehydrational death in anuran amphibians. In Xenopus laevis, a species which experiences hypovolemia from the onset of dehydration (Hillman, 1978a), interference with the physiological responses to falling plasma volume had little if any effect on dehydration tolerance. In Bufo marinus, a species which appears to maintain plasma volume until 20-258 water loss, there is no evidence of hypovolemic shock, even at the point of death. Even so, any conclusions must be constrained by the limitations of these experiments.

Adrenergic blockade in xenopus produced no significant reduction in dehydration tolerance but, for reasons discussed in Chapter $I$, this measure may be insensitive to the effects of the treatments. This experiment was conducted on confined frogs and gave no indication whether or not adrenergic blockade significantly reduced aerobic scope with dehydration. Xenopus responds to dehydration by increasing activity, thought to have adaptive significance in escape from desiccating conditions (Putnam and Hillman, 1977). Such activity might be impossible if blood pressure could not be maintained by sympathetic compensation, and 
"ability to survive dehydration" may be reduced even if "dehydration tolerance" is not.

There was no detectable increase in plasma cathepsin activity due to dehydration in Bufe marinus. It is possible that the splanchnic hypothesis for cathepsin release does not apply to anurans, in that splanchnic hypoperfusion does not result in lysosomal disruption and only infection causes an increase in plasma cathepsin activity. However, hypovolemia does not appear to develop in toads until the water deticit reaches $20-258$ and splanchnic hypoxia may not occur until death is imminent. In any event, plasma cathepsin activity is but one measure of the status of the circulation and may not adequately reflect the consequences of dehydration and hypovolemia in toads.

Regardless of the limitations of these techniques, the results presented here argue against the hypothesis that hypovolemia is a critical factor in dehydrational death in anurans. If hypovolemia were the proximate cause of death in dehydration, one would expect much stronger evidence of the value of sympathetic reflexes or the presence of shock factors. The absence of any convincing evidence for the importance of hypovolemia offers indirect support for the importance of hyperosmolality and increased viscosity in dehydrational death in anurans. 


\section{REFERENCES}

Alvarado, R. H. (1972). The effects of dehydration on water and electrolytes in Ambystoma tigrinum. Physiol. zoole $45: 43-53$.

Anson, M. L. (1936). The estimation of cathepsin with hemoglobin and the partial purification of cathepsin. Je Gene.Physiole 20:565-574.

Ask, J. A. (1983). Comparative aspects of adrenergic receptors in the hearts of lower vertebrates. Comp. Biechem. Physiol. 76A:543-552.

Barrett, A. J. (1969) . Properties of lysosomal enzymes. In Lysosomes in Biology and Patholegy (Vol. 2 ) (J. T. Dingle and H. B. Fell eds.). North-Holland Publishing Co., Amsterdam, pp 245-312.

Barrett, A. J. (197ø). Cathepsin D. Purification of isoenzymes from human and chicken liver. Biecbeme-J. $117: 601-607$.

Barrett, A. J. (1971). Purification and properties of cathepsin $D$ from liver of chicken, rabbit, and man. In Tissue Proteinases (A. J. Barrett and J. T. Dingle eds.). North-Holland Publishing Co., Amsterdam, pp 109-128.

Barrett, A. J. (1973). Human cathepsin Bl: Purification and some properties of the enzyme. Biechem. $J$. $131: 8 \emptyset 9-822$.

Barrett, A. J. (1975). Lysosomal and related proteinases. In Proteases and Biological control (E. Reich, D. B. Rifkin, and E Shaw eds.). Cold Spring Harbor Laboratory, pp 467-482.

Barrett, A. J. (1978). Lysosomal proteinases and their specificity. In protein Turnover and Iysosome Eunction (H. L. Segal and D. J. Doyle eds.). Academic Press, New York, pp 295-3ø4.

Barrett, A. J. (1980). Introduction: The classification of proteinases. In Protein Degradation in Healtb and Disease (D. Evered and J. Whelan eds.). Excerpta Medica, Amsterdam, pp 1-13. 
Barrett, A. J. and H. Kirschke (1981). Cathepsin B, cathepsin $H$, and cathepsin L. In Metbods in Enzymology (Vol. 8l e. Proteolytic Enzymes e Part c) (L. Lorand ed.). Academic Press, New York, pp 535-561.

Bentley, P. J. (1971). Endecrines and Osmeregulation. Springer-Verlag, Berlin.

Bohensky, F. (1982) . Rboto Manual and Dissection Guide ef the Ereg. Avery Publishing Group, Inc., Wayne, NJ.

Bohley, P., H. Kirschke, J. Langner, S. Ansorge, B. Wiederanders, and $\mathrm{H}$ Hanson (1971). Intracellular protein breakdown. In Tissue Proteinases

(A. J. Barrett and J. T. Dingle eds.). NorthHolland Publishing Co., Amsterdam, pp 187-219.

Bond, R. F., E. S. Manning, N. M. Gonzales, R. R. Gonzales, Jr., and V. E. Becker (1973). Myocardial and skeletal muscle responses to hemorrhage and shock during -adrenergic blockade. Ame.Jesbysiole $225: 247-257$.

Chien, S. (1967). Role of the sympathetic nervous system in hemorrhage. Pbysioleney. 47:214-288.

Cotfey, J. W. and C. DeDuve (1968). Digestive activity of lysosomes: $I$. The digestion of proteins by extracts of rat liver lysosomes. J. Biel.echeme 243:3255-3263.

Crie, J. S., P. Morton, and K. Wildenthal (1983). Changes in cardiac cathepsin $B$ activity in response to interventions that alter heart size or protein metabolism: comparison with cathepsin D. Jemoleccelleccardiel. $15: 487-494$.

Crowell, J. W. and A. C. Guyton (1962). Further evidence favoring a cardiac mechanism in irreversible hemorrhagic shock. Am. J. Pbysigl. 203:248-252.

Curtis, M. T. and A. M. Lefer (1980). Protective actions of naloxone in hemorrhagic shock. Am.J. Physiel. 239 : H 416-H42I.

Curtis, M. T. and A. M. Lefer (1981). Beneficial action of naloxone in splanchnic artery occlusion shock. Experientia 37:403-404.

Deyrup, I. J. (1964). Water balance and kidney. In Physiology of the Amphibia (J.A. Moore ed.). Academic Press, New York, pp 251-328. 
Docherty, R., R. J. Carroll, and D. F. Steiner (1982). Conversion of proinsulin to insulin: Involvement of a 31,500 molecular weight thiol protease. Proc. Natle_Acad._Sci._USA 79:4613-4617.

Erıij, D., R. Cetrangolo, and R. Valadez (1965). Adrenotropic receptors in the frog. J. Pbarmacol. Exp. There $149: 65-70$.

Evans, P. and D. J. Etherington (1978). Characterization of cathepsin $B$ and collagenolytic cathepsin from human placenta. Eur.ju. Biecbem. 83:87-98.

Ferguson, W. W., T. M. Glenn, and A. M. Lefer (1972) . Mechanisms of production of circulatory shock factors in isolated perfused pancreas. Ame-Jeshysiole $222: 45 \emptyset-457$.

Glenn, T. M. and A. M. Lefer (1971). Significance of splanchnic proteases in the production of a toxic factor in hemorrhagic shock. CircerRes. 29:338-349.

Glucksman, E. E. and A. M. Lefer (1971). Effects of a myocardial depressant factor on isolated vascular smooth muscle. Am.J._Physiol. 220:1581-1585.

Goettlich-Riemann, W., J. O. Young, and A. L. Tappel (1971). Cathepsins $D, A$, and $B$, and the effect of $\mathrm{pH}$ in the pathway of protein hydrolysis. Biechimesiophys. Acta $243: 137-146$.

Gohda, E. and H. C. Pitot (1981). A new thiol proteinase from rat liver. J. Biel. Cheme 256:2567-2572.

Greenbaum, L. and R. Sherman (1962). Studies on catheptic carboxypeptidase. J._Biele_chem. 237:1082-1085.

Guyton, A. C. (1981). Textbook of Medical Pbysielegy (Sixtb Edition). W. B. Saunders Co., Philadelphia.

Hardaway, R. (1981). Capillary Rerfusion in Healtb and Disease. Futura Publishing Co., Mount Kisco, NY.

Heimburger, N. (1975). Proteinase inhibitors of human plasma - their properties and control functions. In Proteases and Biological Control (E. Reich, D. B. Rifkin, and E. Shaw eds.). Cold spring Harbor Laboratory, pp 367-386.

Herman, C. A. and E. J. Sandoval (1983). Catecholamine effects on blood pressure and heart rate in the 
American Bullfrog, Rana catesbeiana. Gene_comp. Endecrine 52:142-148.

Hillman, S. S. (1978a). Some effects of dehydration on internal distributions of water and solutes in Xenopus laeyis. Compe.Biechem. Physiol. 61A:303-307.

Hillman, S. S. (1978b). The roles of oxygen delivery and electrolyte levels in the dehydrational death of Xepopus laevis. Jeccomp. Pbysiol. 128:169-175.

Hillman, S. S. (1980). Physiological correlates of differential dehydration tolerance in anuran amphibians. copeia 1980:125-129.

Hillman, S. S. (1982). Effects of DL-propranolol on exercise heart rate and maximal rates of oxygen consumption in Scaphiopus intermontanus. Experientia 38:94ø-941.

Hillman, S. S. and R. W. Sommerfeldt (1981). Microsphere studies of amphibian systemic blood flow redistribution during dehydration, hypovolemia, and salt load. Je_Expe_zoole 218:305-3ø8.

Hock, C. E., J. Y. Yu, and A. M. Lefer (1984). Salutary effects of nitrendipine, a new calcium entry blocker, in hemorrhagic shock. Eur. J. Pharmas. 97:37-46.

Iodice, A. A., V. Leong, and I. M. Weinstock (1966). Separation of cathepsins $A$ and $D$ of skeletal muscle. Arch. Biechem. Biopbys. 117:477-486.

Kirby, S. and G. Burnstock (1969a). Comparative pharmacological studies of isolated spiral strips of large arteries from lower vertebrates. Comp. Biochem. Physiol. 28:307-319.

Kirby, S. and G. Burnstock (1969b). Pharmacological studies of the cardiovascular system in the anaesthetized sleepy lizard (Tiligua rugosa) and toad (Bufo marinus). Compe Biocheme Pbysiol. $28: 321-331$.

Kirschke, H., J. Langner, B. Wiederanders, S. Ansorge, and P. Bohley (1977). Cathepsin L: A new proteinase from rat-liver lysosomes. Eur.J._Biechem. 74:293-302.

Lebez, D. and M. Ropitar (1970). Leucocyte proteinases: I. Low molecular weight cathepsins of $F$ and $G$ type. Enzymologia 39:271-283. 
Lebez, D., M. Ropitar, V. Turk, and I. Kregar (1971). Comparison of properties of cathepsins $D$ and $E$ with some new cathepsins. In Tissue_proteinases

(A. J. Barrett and J. T. Dingle eds.) North-Holland Publishing Co., Amsterdam, pp 167-176.

Leter, A. M. (1970). Role of a myocardial depressant factor in the pathogenesis of circulatory shock. Federation Proc, $29: 1836-1847$.

Leter, A. M. (1978). Properties of cardioinhibitory factors produced in shock. Federation Pros. $37: 2734-2740$.

Leter, A. M., R. Cowgill, F. F. Marshall, L. M. Hall, and E. D. Brand (1967). Characterization of a myocardial depressant factor present in hemorrhagic shock. Am._le_physiole 213:492-498.

Leter, A. M. and B. Blattberg (1968). Comparison of the effects of two factors present in plasma of shocked animals. Is_Reticuloendotbel__Soc. 5:54-60.

Leter, A. M. and J. Martin (1970). Relationship of plasma peptides to the myocardial depressant factor in hemorrhagic shock in cats. Cirs._Res. 26:59-69.

Leter, A. M. and Y. Barenholz (1972). Pancreatic hydrolases and the formation of a myocardial depressant factor in shock. Ame_J._Physiol. 223:1103-1109.

Leter, A. M. and G. Papanicolaou (1985). Beneficial actions of two novel calcium entry blockers in the isolated perfused hypoxic cat liver. Metb. Find._Exp._clin. pharmac. 7:59-63.

Letfler, J. N., Y. Litvin, Y. Barenholz, and A. M. Leter (1973). Proteolysis in formation of a myocardial depressant factor during shock. Ame_J._Physiols $224: 824-831$.

Levyant, M. I., V. S. Bylinkina, M. G. Trudolyubova, and V. N. Orekhovich (1976). Presence of a proteinase in polyribosomes of rat liver. Mol._Biol_(USSRL $10: 634-639$.

Levyant, M. I., V. S. Bylinkina, and V. N. Orekhovich (1979). Inhibitors of the ribosomal proteinase cathepsin R: Polyamines as natural inhibitors of the proteinase. Biochem. (USSRL 44:1147-1151. 
Liao, J. C. R. and J. F. Lenney (1984). Cathepsins J and K: High molecular weight cysteine proteinases from human tissues. Biochem._Biopbys._Res._Comm. 124:909-916.

Lillo, R. S. (1979). Autonomic cardiovascular control during submergence and emergence in bullfrogs. Am._._Pbysiol. $237: R 210-R 216$.

Litvin, Y., J. N. Leffler, Y. Barenholz, and A. M. Lefer (1973). Factors influencing the in yitro production of a myocardial depressant factor. Biechem. Med. $8: 199-212$.

Lones, M. and $\mathrm{H}$. Singh (1980). Purification of lung lysosomal cathepsin B2. Federation Prose 39:1862 (Abstract).

Mcuonald, J. R., B. B. Zeitman, T. J. Reilly, and S. Ellis (1969). New observations on the substrate specificity of cathepsin C (dipeptidyl aminopeptidase I). J._Biol._chem. 244:2693-2709.

Mellors, A. (1971). A thiol-dependent cathepsin IV in rat liver lysosomes. Arch._Biechem._Biopbys. 144:281-285.

Mycek, M. J. (1970). Cathepsins. In Methods in Enzymelogy (Yol__XIX, Proteolytic Enzymes) (G. Perlmann and L. Lorand eds.). Academic Press, New York, pp 285-315.

Nakajima, R., J. C. Powers, B. M. Ashe, and M. Zimmerman (1979). Mapping the extended substrate binding site of cathepsin $G$ and human leukocyte elastase: Studies with peptide substrates related to the $\alpha_{1}$-protease inhibitor reactive site. I._Biole_chem. $254: 4027-4032$.

Neurath, H. (1984). Evolution of proteolytic enzymes. science $224: 350-357$.

Otto, R. (1971). Cathepsins B1 and B2. In Tissue Broteinases (A. J. Barrett and J. T. Dingle eds.). North-Holland Publishing Co., Amsterdam, pp 1-25.

Pontremoli, S., E. Melloni, F. Salamino, B. Sparatore, M. Michetti, and B. L. Horecker (1982). Cathepsin M: A lysosomal proteinase with aldolase-inactivating activity. Arche_Biochem._Biophys. 214:376-385.

Press, E. M., R. R. Porter, and J. Cebra (1960). The isolation and properties of a proteolytic enzyme, 
cathepsin $D$, from bovine spleen. Bigchem._J. $74: 501-514$.

Putnam, R. W. and S. S. Hillman (1977). Activity responses of anurans to dehydration. Copeia 1977:746-749.

Rous, P. (1925). The relative reaction within living mammalian tissues. II. On the mobilization of acid material within cells, and the reaction as influenced by the cell state. J__Exp._Med. 41:399-411.

Scnmidt-Nielsen, K. (1964). Desert_Animalss_Physiological Problems_of_Heat_and_Water. Clarendon Press, Oxford.

Sham, J. S. K., V. C. K. Wong, K. W. Chiu, and P. K. T. Pang (1984). Blood pressure homeostasis in Rana

catesbeiana under normal and hypovolemic conditions. comp._Biecbem._Pbysiol. 79C:301-304.

Shcherbak, I. G. and A. A. Zhloba (1979). Activation of cathepsin $B l$ by reduced forms of pyridine nucleotides and thiol compounds. Biocbeme_UUSSR 44:1753-1760.

Shoemaker, V. H. (1964). Physiological effects of water deprivation in a toad, Bufo marinus.

$\mathrm{Ph}$. D. dissertation, University of Michigan.

Smith, V. D. E. and C. M. Jackson (1931). The changes during desiccation and rehydration in the body and organs of the leopard frog (Bana pipiens). Biole_Bulle $60: 80-93$.

Stene-Larsen, G. and K. B. Helle (1978). Cardiac $\beta_{2}$-adrenoceptor in the frog. Comp._Biochem._Pbysiol. $60 \mathrm{C}: 165-173$.

Takahashi, T. and J. Tang (1981). Cathepsin D from porcine and bovine spleen. In Methods in Enzymology (Yol._8l. Proteglytic Enzymes_ Part_Cl (L. Lorand ed.). Academic Press, New York, pp 565-581.

Takio, K., T. Towatari, N. Katunuma, D. Teller, and $\mathrm{K}$. Titani (1983). Homology of amino acid sequences of rat liver cathepsins $B$ and $H$ with that of papain. Proc,_Natl__Acad__Sci__USA 80:3666-3670.

Taylor, S. L. and A. L. Tappel (1974). Identification and separation of lysosomal carboxypeptidases. Biechime Biophys._Acta 341:99-111.

Thorson, T. B. (1955). The relationship of water economy 
to terrestrialism in amphibians. Esology 36:100-116.

Thorson, T. and A. Svihla (1943). Correlation of the habitats of amphibians with their ability to survive the loss of body water. Ecology 24:374-381.

Turnsek, T., I. Rregar, and D. Lebez (1975). Acid sulfhydryl protease from calf lymph nodes. Biochim. Biopbys__Acta 403:514-520.

Usnioda, E., B. Nuwayhid, G, Kleinman, R. Tabsh, C. R. Brinkman III, and N. S. Assali (1983). The contribution of the $\alpha$-adrenergic system to the cardiovascular response to hypovolemia. Am. J. Qbstet._Gynecole $147: 423-429$.

Weder. R. (1957). On the biological function of cathepsin in tail tissue of xenepus larvae. Experientia $13: 153-155$.

Wintroub, B. U., L. B. Klickstein, V. J. Dzau, and $K$. W. K. Watt (1984). Granulocyte-angiotensin system. Identification of angiotensinogen as the plamsa protein substrate of leukocyte cathepsin $G$. Biecheme $23: 227-232$.

Woessner, J. F. (1971). Cathepsin D: enzymic properties and role in connective tissue breakdown. In Tissue Proteinases (A. J. Barrett and J. T. Dingle eds.). North-Holland Publishing Co., Amsterdam, pp 291-308.

Yokota, S. D. and S. S. Hillman (1984). Adrenergic control of the anuran cutaneous hydroosmotic response. Gen._Comp. Endecrin. 53:309-314.

Zar, J. H. (1984) . Biostatistical_Analysis_(Second Edition. . Prentice-Hall, Inc., Englewood Cliffs, NJ.

Zuehlsdorf, M., M. Imort, A. Hasilik, and $R$. von Figura (1983). Molecular forms of $\beta$-hexosaminidase and cathepsin $D$ in serum and urine of healthy subjects and patients with elevated levels of lysosomal enzymes. Biecbem. $J .213: 733-740$. 